
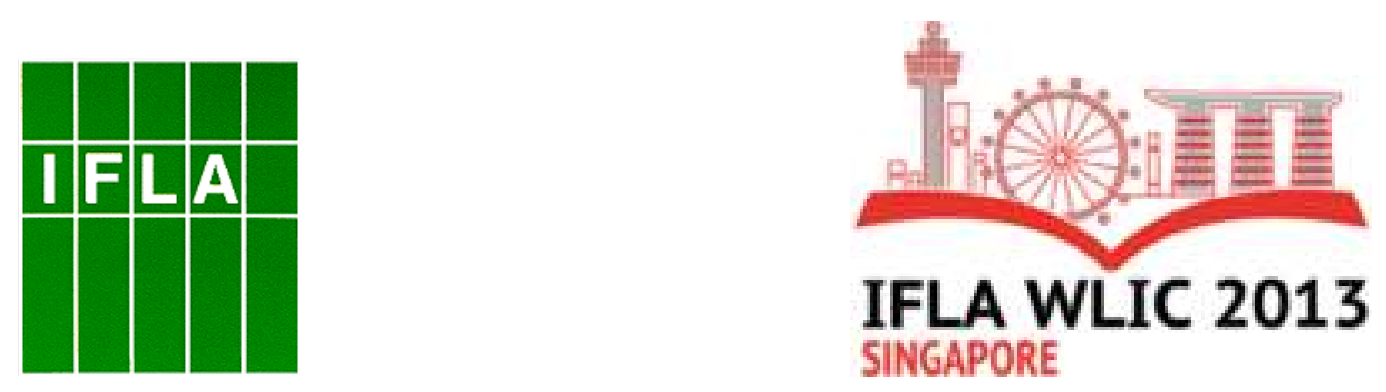

\title{
INTERNATIONAL FEDERATION OF LIBRARY ASSOCIATIONS AND INSTITUTIONS
}

WORLD LIBRARY AND INFORMATION CONGRESS $79^{\text {th }}$ IFLA GENERAL CONFERENCE, SINGAPORE 17-23 AUGUST 2013

\section{STANDING COMMITTEE CATALOGUING SECTION (CATS SC)}

\footnotetext{
Meetings: Standing Committee I (SCI), Saturday, August 17, 9:45-12:15 (Room 304) Standing Committee II (SCII), Thursday, August 22, 9:45-11:15 (Room 309)

Chair: Hanne Hørl Hansen

Secretary: Miriam Säfström
}

MINUTES: SCI .2

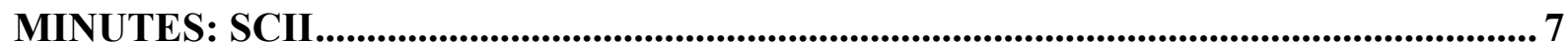

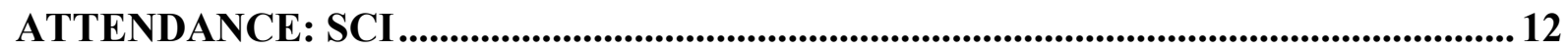

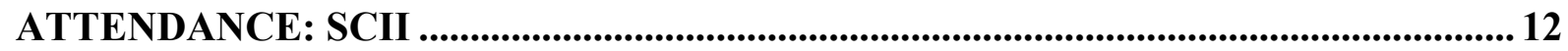

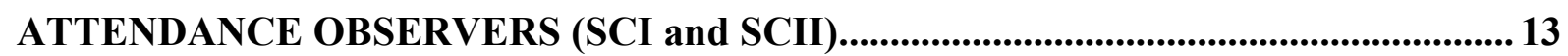

APPENDIX I: FRBR RG: Report of activities 2012-2013 .............................................. 15

APPENDIX II: ISBD RG and ISBD/XML SG: Activity report 2012-2013 ...................... 17

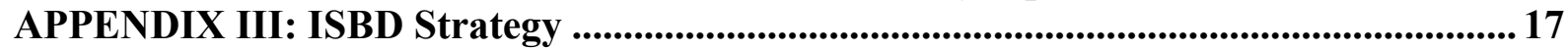

APPENDIX IV: ISBD Strategy: ISBD RG comments 1 (2) ................................................ 22

APPENDIX V: ISBD Strategy: ISBD RG comments 2 (2).................................................. 24

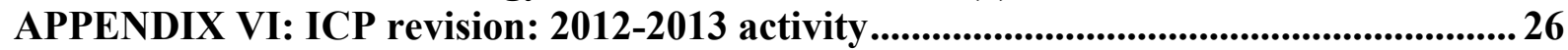

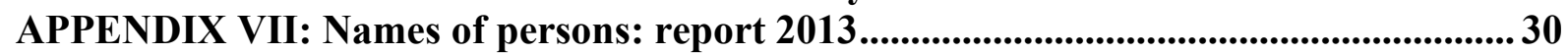

APPENDIX VIII: Report from ALA CC:DA, ALA Midwinter Conference 2013 .......... 32

APPENDIX IX: Report from ALA CC:DA, ALA Annual Conference 2013 ................... 34

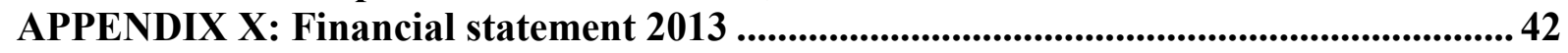

APPENDIX XI: Draft strategic plan ........................................................................... 48

APPENDIX XII: Update on Singapore meetings: FRBR RG..............................................5 51

APPENDIX XIII: Update on Singapore meetings: ISBD RG.............................................. 55

APPENDIX XIV: Report from ISO TC46 Annual meetings 2013 ...................................... 56 


\section{MINUTES: SCI}

Standing Committee I: Saturday, 17 August, 9:45-12:15, Room 304

For attendance, see "Attendance SCI" and "Attendance observers SCI and SCII"

\section{Welcome and introductions}

The chair, Hanne Hørl Hansen, welcomed all Standing Committee (SC) members, and observers. This was followed by brief introductions of the SC members, as well as of the observers.

\section{Agenda}

The Professional Committee (PC) has asked all sections to add to the meeting agenda a discussion about "SC Roles and Responsibilities" so that everyone understands what is expected in the different roles. A summary of IFLA SC roles and responsibilities can be found at http://www.ifla.org/officers-corner/sc-members. The PC wishes to stress that SC members are expected to participate in and contribute to the work and activities of the $\mathrm{SC}$, its working groups and sub-committees, and also that $\mathrm{SC}$ members who do not attend two consecutive committee meetings and does not provide a reasonable explanation for their absence to the chair shall be considered to have resigned.

All SC members approved the agenda with this addition.

\section{Minutes of 2012 meetings in Helsinki}

The minutes (http://www.ifla.org/files/assets/cataloguing/reports/meeting_2012.pdf and http://www.ifla.org/files/assets/cataloguing/reports/appendix_x.pdf) were approved as written.

\section{Elections}

\subsection{Election of officers and information coordinator}

The current chair Hanne Hørl Hansen and secretary/treasurer Miriam Säfström were elected for another two-year term. The current information coordinator Agnese Galeffi was also elected for another two-year term.

\subsection{Review group (RG) members}

FRBR RG elections

The FRBR RG had three vacancies as Rajesh Chandrakar, Pat Riva (chair) and Maja Žumer all finished their terms. The call for nominations resulted in the following nominations:

- Patrick Le Boeuf, France

- Tanja Merčun, Slovenia

- Anke Meyer-Hess, Germany

- Chris Oliver, Canada

- Athena Salaba, USA

The statutes for the FRBR RG say that the group should have no less than eight and no more than ten members. The RG chair proposed that the group should be expanded to ten members. This would allow for all the nominees to join. A larger group would be very useful in the consolidation work that is the main focus of the RG right now. The SC approved of this expansion. 
The FRBR RG now consists of the five newly-elected members (serving their first 4-year terms), and:

- Gordon Dunsire (just starting his second 4-year term),

- Elena Escolano Rodríguez (in the middle of her first term which ends 2015),

- Françoise Leresche (in the middle of her second term which ends 2015),

- Filiberto Felipe Martínez (in the middle of his first term which ends 2015) and

- Miriam Säfström (just starting her second 4-year term)

The group will discuss the matter of a new chair during this conference, as Riva is now leaving the $\mathrm{RG}$ after her second 4-year term.

\section{ISBD RG elections}

Renate Gömpel, Ben Gu, Dorothy McGarry and Glenn Patton are all leaving the group after serving two 4-year terms. The ISBD RG made a call for nominations and received the following names:

- Maria Violeta Bertolini, Argentina

- Lynne Howarth, Canada

- Ricardo Santos Munoz, Spain

These nominations were all approved, and the three new members will start serving their first 4-year term. It was suggested that outgoing member Dorothy McGarry would continue her work in the RG as an honorary member, which the SC welcomed and approved. In addition to the four mentioned above, the ISBD RG consists of:

- Anders Cato,

- Agnese Galeffi,

- Massimo Gentili-Tedeschi (all three in the middle of their first term which ends 2015),

- Ben Gu (in the middle of his second term which ends 2015),

- Tuula Haapamäki (just starting her second 4-year term),

- John Hostage (in the middle of his second term which ends 2015),

- Natalia Kasparova,

- Irena Kavcic,

- Francoise Leresche (all three just starting their second 4-year term),

- Mirna Willer (chair) (in the middle of her first term which ends 2015)

\subsection{Corresponding members}

This year the SC got a new corresponding member from The National Diet Library, Japan. Atsushi Tashiro replaces Shiho Ueda. The chair has contacted a number of libraries in countries that lack SC representation (Australia, India, Africa) but has so far not received any answers.

\subsection{Thanks to outgoing members}

The following members are leaving the Standing Committee:

- Ana Barbaric (former section secretary, SC member since 2005) 
- Anders Cato (former section chair, former section secretary/treasurer, SC member since 2005)

- Ben Gu (former section secretary, SC member since 2005)

- Patrizia Martini (SC member since 2009)

- Pat Riva (outgoing chair of the FRBR RG, SC member since 2005)

- Bettina Wagner (SC member since 2009)

They all received warm thanks for their work for the Cataloguing Section and a certificate from IFLA Headquarters.

\section{Announcements}

\subsection{Division and Section Programmes}

The chair announced the section programme to be held on Tuesday 20 August 9:30-12:45. The session is a joint venture with the Audiovisual \& Multimedia Section titled "Macro and micro - ways through the maze. How new methods of indexing and cataloguing can complement traditional cataloguing for audiovisual and multimedia" The session includes the following papers:

Keynote: Opening up access to multimedia content Adam Farquhar (British Library, London, UK)

Keynote 2: Increasing functionality and usage of video so it may gain its rightful place in the academy

Stephen Rhind-Tutt (Alexander Street Press, USA)

TIB's portal for audiovisual media: new ways of indexing and retrieval Janna Neumann and Margret Plank (German National Library of Science and Technology, Germany)

Ontology based framework for real-time audiovisual art Canan Hastik, Arnd Steinmetz and Bernhard Thull (University of Applied Sciences, Germany)

Building a sustainable metadata workflow for audio-visual resources: University of Illinois Library's Medusa Digital Preservation Repository Ryan Edge and Myung-Ja Han (University of Illinois at Urbana-Champaign, USA)

Learning from the SCI-Arc Media Achieve

Kevin McHanon (Southern California Institute of Architecture Media Archive, USA)

\subsection{Thanks to translators}

The chair extended her warm thanks to all translators who have helped with the programme papers.

\subsection{Strategic input: Professional units key initiatives session}

At least one representative from each section must attend the Professional units key initiatives session (Tuesday 20 August). The person attending should bring a copy of the section's 
current Action plan and be ready to contribute actively to the discussions with GB members. Unfortunately this session collides with the CATS's open programme. It was decided that secretary Säfström should attend the session on key initiatives.

\section{Reports I}

6.1 FRBR RG and subgroups

Pat Riva, chair of the FRBR Review Group (RG), presented a report of activities of the FRBR RG 2012-2013 (Appendix I).

\subsection{ISBD RG and ISBD/XML Study Group}

Mirna Willer, chair of the ISBD Review Group (RG), presented a report of activities of the ISBD RG and the ISBD/XML Study Group for the period 2012-2013 (Appendix II).

\subsection{IFLA Namespaces Task Group}

The IFLA Namespaces Task Group (TG) is affiliated with the Classification and Indexing Section, but its work is of great interest to the Cataloguing Section. Gordon Dunsire chairs the group. Reports of the TG activities can be found at http://www.ifla.org/node/5353.

\subsection{IFLA Committee on Standards}

Patrice Landry reported from the IFLA Committee on Standards. The Committee supports and advises the Professional Committee (PC) on standards-related work (not only bibliographic standards). During its first year, the Committee has made an inventory of standards and standard-like texts produced by the different IFLA sections. It is clear that there is a difference between the bibliographic standards and many other IFLA "standards" (guidelines/manifests and such). The work with bibliographic standards must be considered an on-going activity, not projects. This has been obvious in the funding of the efforts, when on-going standard maintenance has to be expressed as two-year projects to apply for IFLA funding. The groups working with these standards; FRBR RG, ISBD RG, the Namespaces TG, and the Permanent UNIMARC Committee (PUC) are not project groups but rather permanent groups that are needed to keep the standards up-to-date and usable for the community.

Landry welcomed the discussion that has started within the Cataloguing Section, about our role in standards development and how we can best focus our efforts and make responsible use of our resources. The ISBD group is planning a survey to get more information on how/by whom ISBD is used. Landry said that the Committee on Standards was also planning surveys, for other IFLA documents and products, to get a grip on how the community is using them. The committee also plans a satellite meeting in 2015 where the subject will be "impact of IFLA standards". He hoped for many papers from the former Division IV (i.e. Cataloguing, Classification and Indexing, and Bibliography).

\section{Future Strategy for the ISBD}

The different documents submitted (see appendix III-V) were discussed.

The discussion revolved around a number of open questions the section must consider. On a high level the strategic questions can be summarized: How can we best focus the section efforts? How does the section best contribute to the "eco-system of standards" in a changning world? 
Many good points were raised. Today the ISBD forms the basis for many cataloguing codes, but it is also used as a cataloguing rule in itself (with complementing local guidelines). It is a strategic choice for the Cataloguing Section whether:

a) to meet the demands of these communities for a complete cataloguing code (complete in itself) or

b) to work towards evolving the ISBD to a shorter, more principle-based, standard that would still be able to form the basis for other codes but also could be used by itself, or with complementing documents (as is done today).

Some factors that have impact on the strategy are:

- the feasibility of developing and maintaining a modern cataloguing code with volunteer work;

- whether any code in today's linked universe need to be "complete in itself".

This is not a question of the ISBD versus RDA, but RDA is of course a big factor in the UBC environment. This has been recognized in the work with aligning the two standards (of course RDA - as its predecessor AACR2 - builds on ISBD). When deciding on a future strategy the section must address whether the two communities should continue working in parallel and mapping/aligning the result of each others' work, or if it may be useful to look at other ways of cooperation.

It should also be stated that the section is in no way proposing to discontinue the ISBD work.

A roadmap for the work strategy had earlier been proposed:

- IFLA WLIC 2013 - preliminary discussions in SC, ISBD RG and involving the SC of the Bibliography Section.

- The ISBD RG is planning a survey about ISBD and the ISBD RG will afterwards look into the result.

- It is also suggested that the issue will be raised on CATSMAIL and we will encourage institutions and groups to express their opinions.

- Announcement about the survey and the invitation, as well as deadlines, must be coordinated.

- Spring/summer 2014: The officers of the Cataloguing Section will look at the results of these initiatives and prepare a basis for a decision on future strategy (see above) for IFLA WLIC 2014.

This roadmap was approved by the section, with the addition that the SC members wanted to see and approve of the survey before it is sent out. The ISBD RG agreed to this. The SC chair will apply for an extra 2- or 3-hour slot at next years' meeting, where we can discuss the question before reaching a decision. In the meantime all SC members are encouraged to discuss the questions via email.

\section{Revision of ICP}

A group of $\mathrm{SC}$ members has looked into the question of an International Cataloguing Principles (ICP) revision and identified two possible paths (see Appendix VI)

1) To assume that the ICP structure is still good, and we just need to update the topics that since 2009 have seen some kind of evolution. 
2) To decide that what is needed is not just an update but a deep change in the structure of the document.

The recommendation is to go with the first alternative. The group members (Agnese Galeffi, Dorothy McGarry and Dave Reser) volunteered to make a draft ICP version. Other volunteers are also welcome.

9. Adjournment

The chair adjourned the meeting

\title{
MINUTES: SCII
}

\author{
Standing Committee II: Thursday, 22 August, 9:45-11:15, Room 309 \\ For attendance, see "Attendance SCI" and "Attendance observers SCI and SCII"
}

\section{Welcome}

The chair, Hanne Hørl Hansen, welcomed all Standing Committee (SC) members and observers to this second meeting of the CATS SC. This was followed by brief introductions of the SC members and the observers.

\section{Agenda}

The agenda was updated with some items (inserted below). The meeting started with items that we had no time to discuss at SCI.

\section{Names of Persons, Anonymous Classics - status and future}

Anders Cato reported on the status of Names of Persons. See Appendix VII. The report, prepared by Cato and Leresche, proposes that a part of the CATS web site should be devoted to Names of Persons, in the same way as a page of it is already devoted to the International Cataloguing Principles and all the translations in which they are available. For the management of the page a form should be created. This form can be filled in by the various countries in order to document their policies. The form should also allow for the uploading of files (with the date of update). The Cataloguing Section might benefit from getting in touch with the Bibliography Section, whose National Bibliographic Register is managed in that way, and from drawing inspiration from the Bibliography Section's method and organization. This suggestion was approved by the CATS. Cato and Leresche continue working with the question, with the help of information coordinator Galeffi.

A similar solution could work for Anonymous classics. The situation here is that the African list is only published in draft form, and that we lack a list from Latin America. Despite our efforts, the section has no member/corresponding member from Africa. It was however noted that this meeting was attended by observers from Nigeria (from the National Library and the University of Ibadan) which could help to check the draft. Chair Hanne will take on the task to coordinate this. As for Latin American representation, the section now has a representative from Argentina, Maria Violeta Bertolini. Bertolini agreed to take on the task to locate the information needed. Hansen and Bertolini will report on their respective progress next year.

\section{Reports II}

13.1 American Library Association' Committee on Cataloging: Description and Access 
Jay Weitz, liaison to the American Library Association' Committee on Cataloging: Description and Access (ALA CC:DA), presented two reports from the Committee meetings at ALA Midwinter and the ALA annual conference (See Appendix VIII-IX).

\subsection{SCATNews}

Newsletter editor Unni Knutsen told the SC members that SCATnews has been published according to plan, that is, twice since our last SC meeting. In December 2012 an online survey of the newsletter was closed. The survey showed that the newsletter was appreciated. The content was considered good. The newsletter contains information about the work of the section, with the chairs of the work and review groups as regular contributors. The survey also showed an interest in news from other section members, about regional conferences and such. What could be improved is perhaps the newsletter layout. Knutsen and Galeffi has already given it a "face lift" to make it more appealing and web friendly. This means more pictures, a clearer layout and short summaries of the articles.

The deadline for the next issue of SCATNews is December $1^{\text {st }}$. In this Knutsen would like to include pictures of all newsletter article authors.

\subsection{IFLA website}

Agnese Galeffi, CATS information coordinator, reported about her work with the website. Last year, the section discussed how/whether to use social media as an information channel. After some thought, she decided against it, and will instead focus on making the website more dynamic, with news from the section and the working/review groups. SC member Bertolini offered to help gathering content, should this be needed.

As a start Galeffi would like to have pictures and short biographies from the ongoing and incoming SC members.

\subsection{MulDiCat}

Last year Anders Cato and Gordon Dunsire reported that $90 \%$ of the MulDiCat content had been published in the Open metadata registry (OMR) (http://metadataregistry.org/vocabulary/show/id/299.html). To publish the terminology in this way makes it easier to take advantage of the multilingual content and allows for full version control. The OMR framework allows for other types of content (terminology) and could be a valuable resource for all IFLA sections, not only those involved in bibliographic control. The next step is to make it possible for new translations to be incorporated by the translators themselves. As it is now a Russian version has been delivered, but as Gordon Dunsire is the only one with technical access to the service, it cannot be added. Dunsire lack the Russian knowledge to add the content, and the Russian translators lack the technical access to OMR. This project awaits funding and has not been achieved yet.

\section{Announcements}

\subsection{Leadership forum of the Library services division}

Chair Hansen reported from the Leadership forum. Division III (Library services) has a new chair, Maria-Carme Torras i Calvo from Bergen University College in Norway.

A topic raised at the Leadership forum was how to engage the SC members taking on tasks. Many section officers considered it a problem that the SC members were passive, did not participate in the discussion during meetings, take on tasks, or even answer emails. The forum 
stressed that SC members are expected to participate in and contribute to the work and activities of the SC (see also "2. Agenda" above).

The Division III identity was also discussed. The division Library services is very broad in its scope, and it is hard to find a unifying identity. The pragmatic way to look at it is not to try to find a common identity, but rather consider the division a practical way of gathering sections that indeed serve the library community, but in very different ways.

\subsection{Professional units key initiatives session}

Säfström reported from the Professional units key initiatives session, which was held at the same time as the CATS open programme. Attendees was gathered in discussion groups based on which IFLA division they represented. Governing Board (GB) and Professional Committee (PC) members then led round table discussions on selected topics. The two themes discussed in the division III Library services group was the newly published IFLA trend report (http://trends.ifla.org/). In the CATS strategic plan, we should aim to tie our work to the trends identified in the report.

The standards work of the organisation was also discussed in a round table manner. The important question of funding of the ongoing standards work has been discussed by the IFLA PC, and according to Ann Okerson, outgoing PC chair, a new funding model was envisioned. In the future, funds will be set aside for the ongoing work, and it does not have to be expressed as project work. Exactly how to solve this is not yet determined. The importance of IFLA work in the area of bibliographic standards was stressed. This could well be an IFLA key initiative.

The newly launched IFLA library (http://library.ifla.org/) was also discussed. Säfström mentioned that the service could benefit from some metadata expert help, and professional support officer Joanne Yeomans promised to get back to the section.

\section{Finances}

Säfström presented the Financial report including a draft budget for next year (Appendix X). At the FRBR RG meeting it had been suggested that the SC administration funds could be used to keep the domain www.frbr.org, a proposal the SC supported.

\section{Strategic Plan 2013-2015 /Action plan 2013}

According to IFLA instructions the sections must formulate action plans, listing at least three actions. Last year, the chair drafted an action plan and sent it to the SC members, after which it was incorporated into the strategic plan.

At last year's meeting it was concluded that "the CATS should not aim to form an international cataloguing code. The Cataloguing Section should however continue to take a leadership and partnership role in international cataloguing work. CATS products such as the ICP, the FR family and the basic elements for descriptive cataloguing from the ISBD form the backbone of evolving cataloguing codes such as RDA."

As a consequence of this it was decided that 1.4 in the strategic plan should be deleted. A draft of the strategic plan was discussed. As the section had been informed that the plan should now also relate to the IFLA trend report (http://trends.ifla.org/) it was decided that 
Säfström would make another draft and circulate it via email. See Appendix XI for the draft plan that was discussed at the 2013 meeting.

\section{Evaluation of CATS programme 2013}

This year's open session was arranged together with the Audiovisual \& Multimedia Section. The joint session was considered good, with some very interesting presentations. The paper submission process has however once again been less than satisfactory. It seems that in our fast-moving world papers are seldom written on speculation. In the future the SC would like to try to invite interesting speakers, rather than having a traditional call for papers. These two methods can of course also be combined.

\section{Future CATS programmes}

18.1 80th WLIC in Lyon, August, 2014

The theme for IFLA WLIC 2014 is "Libraries, Citizens, Societies: Confluence for Knowledge". It has been suggested for the CATS open session to focus on universal bibliographic control (UBC). This interesting idea was discussed by the SC. For 2015 the Committee on Standards is planning a satellite meeting on the impact of IFLA standards, a satellite to which our section (together with Classification and Indexing, Bibliography and the Permanent UNIMARC Committee) has been specially encouraged to contribute. As the section has an ongoing discussion about our strategic plan and what we want to achieve and how we should direct our efforts, it might be a bit premature to present any SC views on this.

What could be the focus of an open session is what "bibliographic control" means today; "bibliographic control in practice". There seems to be an interest with our sibling sections to work with this, maybe we could combine our slots to make it a longer, or even a full-day event. The title "UBC and use/reuse of metadata" was proposed. The section chairs (CATS: Hansen, BIBS: Anders Cato and Classification and Indexing: Maja Žumer) will discuss this proposal further and come back to the SC members to form a programme committee. The Permanent UNIMARC Committee (PUC) also indicated that it might want to be involved in such a joint venture.

\subsection{Satellite meeting 2014}

Next year the SC will arrange a satellite meeting on RDA. This will be follow-up to the 2011 meeting. The Deutsche Nationalbibliothek has offered to host the satellite meeting, which will take place August $13^{\text {th }}$ in Frankfurt. A conference committee will be established (via email) to put together the programme. The SC recommended a mix of invited speakers and a call for papers.

The Information Technology Section and the Semantic Web Special Interest Group will arrange a satellite meeting on linked data in Paris the 14 August. The IFLA WLIC will take place in Lyon 16-22 August.

\section{Reports}

\subsection{Current projects: update on Singapore meetings}

The FRBR Review Group held two meetings during the IFLA WLIC, one business meeting and one working meeting. At the meeting on August 18 the incoming and continuing RG members present proposed Chris Oliver as the new chair of the FRBR RG. This recommendation was approved by the CATS SC. The main focus of the RG is consolidation of the FR family of conceptual models. It was proposed that an Editorial Working Group 
should be appointed to guide the editorial work on the consolidated models document. Members: Patrick Le Boeuf, Miriam Säfström, Pat Riva and Maja Žumer. This was also approved by the CATS SC.

A working meeting focusing on model consolidation will be held at the BnF in Paris. There is money available for 2013, the main difficulty was finding a date. It was decided to hold the meeting in late October, just before a scheduled ISBD RG and ISBD/Linked data WG meeting, and a CIDOC CRM meeting in Heraklion. (See Appendix XII.)

The ISBD Review Group held two meetings during the IFLA WLIC. The incoming and continuing RG members present proposed renewal of Mirna Willer as chair of the ISBD RG. This recommendation was approved by the CATS SC. At the meetings the CATS strategic plan was discussed. Other topics were the planned survey of ISBD use, which will be informative for the ongoing process. The ISBD/RDA alignment work is ongoing.

The ISBD/XML Study Group has been renamed the ISBD Linked Data Study Group to better reflect the work being done. (See Appendix XIII.)

\subsection{Reports from other institutions}

Report from ISO TC46: The committee liaison, Paola Manoni, has sent a report on ISO TC46 activities 2013. (See Appendix XIV).

\section{Adjournment}

The chair thanked all those present and adjourned the meeting. 


\section{ATTENDANCE: SCI}

Standing Committee members present:

Manal Amin Abdelhalim (incoming member)

Library of Congress, USA

Maria Violeta Bertolini (incoming member)

Anders Cato (outgoing member)

Henriette Fog (incoming member)

IFTS No. 13, Argentina

BTJ, Sweden

Royal Library, Copenhagen University

Christine Frodl

Library, Denmark

Agnese Galeffi

Massimo Gentili-Tedeschi (incoming member)

Tuula Haapamäki

Hanne Hørl Hansen

Deutsche Nationalbibliothek, Germany

Vatican School of Library Science, Italy

Biblioteca Nazionale Braidense, Italy

National Library of Finland

Unni Knutsen

Patrick Le Boeuf (incoming member)

Françoise Leresche

Dorothy McGarry

Pat Riva (outgoing member)

Miriam Säfström

Jay Weitz

Danish Library Center, Denmark

Oslo University Library, Norway

Bibliothèque nationale de France

Bibliothèque nationale de France

University of California, Los Angeles, USA

Bibliothèque et Archives nationales du Québec, Canada

National Library of Sweden

OCLC, USA

Standing Committee members absent:

Ana Barbarić (outgoing member)

Viktoria Barsukova

Hong Gao (incoming member)

Ben Gu (outgoing member)

Cha Kyung Lee

Filiberto Felipe Martínez Arellano

Patrizia Martini (outgoing member)

Milena Milanova

David Reser

Bettina Wagner (outgoing member)

University of Zagreb, Croatia

National Library of Russia

National Library of China

National Library of China

National Bibliographic Control Center,

National Library of Korea

National University of Mexico

ICCU, Italy

Sofia University, Bulgaria

Library of Congress, USA

Bayerische Staatsbibliothek, Germany

\section{ATTENDANCE: SCII}

Standing Committee members present:

Manal Amin Abdelhalim (incoming member)

Maria Violeta Bertolini (incoming member)

Henriette Fog (incoming member)

Christine Frodl

Agnese Galeffi

Massimo Gentili-Tedeschi (incoming member)

Tuula Haapamäki

Hanne Hørl Hansen

Unni Knutsen

Library of Congress, USA

IFTS No. 13, Argentina

Royal Library, Copenhagen University

Library, Denmark

Deutsche Nationalbibliothek, Germany

Vatican School of Library Science, Italy

Biblioteca Nazionale Braidense, Italy

National Library of Finland

Danish Library Center, Denmark

Oslo University Library, Norway 
Françoise Leresche

Dorothy McGarry

Pat Riva (outgoing member)

Miriam Säfström

Jay Weitz

\section{Standing Committee members absent:}

Ana Barbarić (outgoing member)

Viktoria Barsukova

Anders Cato (outgoing member)

Hong Gao (incoming member)

Ben $\mathrm{Gu}$ (outgoing member)

Patrick Le Boeuf (incoming member)

Cha Kyung Lee

Filiberto Felipe Martínez Arellano

Patrizia Martini (outgoing member)

Milena Milanova

David Reser

Bettina Wagner (outgoing member)
Bibliothèque nationale de France

University of California, Los Angeles, USA

Bibliothèque et Archives nationales du Québec, Canada

National Library of Sweden

OCLC, USA

University of Zagreb, Croatia

National Library of Russia

BTJ, Sweden

National Library of China

National Library of China

Bibliothèque nationale de France

National Bibliographic Control Center,

National Library of Korea

National University of Mexico

ICCU, Italy

Sofia University, Bulgaria

Library of Congress, USA

Bayerische Staatsbibliothek, Germany

\section{ATTENDANCE OBSERVERS (SCI and SCII)}

Harriet Aagaard
Latifa Al-Qubaisi
Kulthum Ali
Carsten Andersen
Marie Balikova
Julianne Beall
Vincent Boulet
Maureen Chew
Gordon Dunsire
Angela Green
Victoria Hentschel
Lynne Howarth
Minyoung Hwang
Jacob O Kutu
Patrice Landry
Jaesun Lee
Sinikka Luukkanen
Erlinda T Malinis
Tatiana Maskhulia

Stockholm Public Library, Sweden

ADVTI Library, Abu Dhabi

Zayed University

Danish Bibliographic Center

National Library of the Czech

Republic

Library of Congress, USA

Bibliothèque nationale de France

City of Canning Public library,

Australia

Consultant, UK

Texas A\&M at Quatar, Quatar

German National Library

Faculty of Information, University of

Toronto, Canada

National Library of Korea

University of Ibadan, Nigeria

Swiss National library

National Library of Korea

National Library of Finland

NKTI Medical library

Presidential Library, Russia

$\begin{array}{ll}\text { SCI } & \text { SCII } \\ \text { X } & \text { X } \\ & \text { X } \\ & \text { X } \\ \mathrm{X} & \\ & \mathrm{X} \\ & \\ \mathrm{X} & \mathrm{X} \\ \mathrm{X} & \\ \mathrm{X} & \\ & \\ \mathrm{X} & \mathrm{X} \\ \mathrm{X} & \mathrm{X} \\ & \mathrm{X} \\ \mathrm{X} & \mathrm{X} \\ & \\ & \mathrm{X} \\ & \mathrm{X}\end{array}$

$\mathrm{X}$

$\mathrm{X}$

$\mathrm{X}$

$\mathrm{X}$ 
F K Olajide-Williams

Chris Oliver

Tadahiko Oshiba

Lolade F Osinulu

Adetoun A Oyelude

Ifeoma Pedro

François-Xavier Pelegrin

George Prager

Ouf Rehab

Alisia Revitt

Sandy Roe

Samba Sako

Robyn Schofield

Beacher Wiggins

Mirna Willer

Shirley Yang Xinping

Maja Žumer
University of Ibadan, Nigeria

McGill University, Montreal, Canada

National Diet Library, Japan

University of Ibadan, Nigeria

University of Ibadan, Nigeria

National Library of Nigeria

ISSN International Centre, France

NYU Law School

Bibliotheca Alexandria

Maine State Library, USA

Cataloging \& Classification Quarterly, editor-in-chief

Directeur de la Recherche et de la X

Documentation, ENA

University of Notre Dame, Australia

Library of Congress, USA

University of Zadar, Croatia

NLB

University of Ljubjana, Slovenia

$\begin{array}{ll} & \mathrm{X} \\ \mathrm{X} & \mathrm{X} \\ \mathrm{X} & \mathrm{X} \\ & \mathrm{X} \\ & \mathrm{X} \\ & \mathrm{X} \\ \mathrm{X} & \mathrm{X} \\ \mathrm{X} & \mathrm{X} \\ \mathrm{X} & \mathrm{X} \\ & \mathrm{X} \\ \mathrm{X} & \mathrm{X} \\ & \\ \mathrm{X} & \\ & \\ & \mathrm{X} \\ \mathrm{X} & \mathrm{X} \\ \mathrm{X} & \mathrm{X} \\ & \mathrm{X} \\ & \mathrm{X}\end{array}$




\section{APPENDIX I: FRBR RG: Report of activities 2012-2013}

\section{Publications}

Following IFLA WLIC in Helsinki, the FRBR RG sent a message to the GB, PC and CLM reiterating our concern that IFLA standards be made available in open access to encourage uptake and use. Permission to post the English text of the Functional requirements for authority data (FRAD) in open access on the IFLA website was obtained from De Gruyter in March 2013. The file being posted is an updated version including the modifications and errata published in fall 2011, as well as a small number of additional errata being published in summer 2013. These latest corrections mainly stem from the work of the Japanese translation team. A separate errata file is being issued for those needing to identify the exact changes, such as for updating translations.

Several more translations of models in the FR family were completed and published in 20122013. FRBR was translated into Arabic by Doaa Ali Mohamed Ali from the Department of Librarianship, Archives and Information Science, Faculty of Arts, Cairo University, this translation was published on the IFLA website. FRBR is now available in all seven IFLA languages; there are 20 translations of FRBR available.

The translation of FRAD into Japanese (by the National Diet Library) was completed and published online, and the citation to the Croatian translation which was published in print in 2010 was added to the listing, bringing the number of completed translations of FRAD to eleven (including six of the IFLA languages). An additional three translations of FRSAD were completed. The Chinese translation and the Russian translation (prepared by a team from the National Library of Russia including Elena Zagorskaya) were published online, while the Croatian translation was published in print. FRSAD is available in five IFLA languages.

The monograph version of The FRBR Family of Conceptual Models: Toward a Linked Future, edited by Richard P. Smiraglia, Pat Riva and Maja Žumer was published by Routledge in June 2013. The collection was first published as a special theme issue of Cataloging \& Classification Quarterly v.50, no.5/7 (2012).

\section{Consolidation of IFLA Conceptual Models}

The RG held two half-day working meetings in conjunction with IFLA WLIC in Helsinki to continue the consolidation work, August 10 and 16, 2012. A draft of the entities needed in the consolidated model was completed and analysis began on the relationships.

The RG submitted a proposal for a 2-year (2013-2014) funded project to allow for the continuation of the consolidation work, particularly to permit mid-year working meetings to take place. The first year of the project titled Reassessment of properties in a consolidated conceptual model was approved in January 2013. The process required the submission of a multi-year planning proposal for the RG's work, this comes in a context where IFLA is seeking a model for funding ongoing standards-related work.

The International Working Group on FRBR-CRM Harmonisation held two meetings in 20122013, completing the extension of FRBRoo to include the entities, attributes and relationships from FRAD and FRSAD. The 20th FRBR-CIDOC CRM meeting was held at the Cultural Heritage Agency of Netherlands (Rijksdienst voor het Cultureel Erfgoed, or RCE) in Amersfoort, Netherlands, on November 19-22, 2012. 
One member of the FRBR RG was funded to attend using the balance of the 2012 project funds. The editorial work and refinement of FRBRoo version 2.0 was completed. The $21 \mathrm{st}$ FRBR-CIDOC CRM meeting was held at the National Archives in Stockholm, Sweden, June 3-7, 2013. At this point version 2.0 of FRBRoo is ready for formal approval and publication.

\section{Namespaces}

FRBRoo version 2.0 is currently available as an RDFS/XML file from the CIDOC CRM website. Its integration into the Open Metadata Registry is planned. This would complete the registration of namespaces for the existing versions of the FR family of models, as namespaces for FRBRer, FRAD and FRSAD were completed in early 2012.

\section{Liaison Activities}

This year the FRBR RG created a new liaison position with the international ISSN Centre. The Cataloguing Section ratified the appointment of François-Xavier Pelegrin as liaison. Gordon Dunsire (already a member of the RG) was confirmed as the new liaison with the JSC.

Pat Riva attended the second international Linked Open Data in Libraries, Archives, and Museums Summit (LODLAM) held June 19-20, 2013 in Montreal, Canada. During a discussion group on FRBR, new contacts were made which may lead to a renewal of crosscommunity work with the archival community.

\section{Distribution List}

The frbr@infoserv.inist.fr list currently has 802 subscribers, a slight decrease. Pat Riva and Patrick LeBoeuf remain the co-listowners. The automated list archive starting in December 2010 is accessible from http://infoserv.inist.fr/wwsympa.fcgi/arc/frbr.

This report is my last as chair. The years since I took over from Patrick Le Boeuf in 2005 have just flown by. My last update to SCATNews (\#39, p.10-11) serves as a retrospective of my whole term. Much has been accomplished, although so much is still to be done. I'd like to extend personal thanks to all the members of the Review Group and it Working Groups during this time, it has been a pleasure to work together. The enthusiastic responses to the call for nominations is very encouraging, I know that the Review Group will be in good hands.

Pat Riva

Chair of the FRBR Review Group

July 31, 2013 


\title{
APPENDIX II: ISBD RG and ISBD/XML SG: Activity report 2012-2013
}

\section{I.}

\author{
Cataloguing Section's ISBD - Strategic Plan
}

After the August meeting in San Juan in 2011 the ISBD RG adopted its Plans for activities 1 aligned with the Cataloguing Section's Strategic Plan², and subsequently proposed a three part project Interoperability of ISBD within Linked Data Environment ${ }^{3}$ for 2012.The project was not approved for funding, and the chair of the Cataloguing Section was asked by the Professional Committee to "develop a strategic plan to address the maintenance and development of ISBD so that the PC has a clear understanding of the priorities, resources, needs and outputs." The Strategic Plan, prepared by H.H. Hansen, M. Säfstrom and M. Willer, was discussed and approved by the ISBD RG and CS's Standing Committee, and sent to the Professional Committee on 15 August 2012.

The plan takes into account the Cataloguing Section's revised action plan for 2013 adopted at its 2012 meeting: (1) consolidation of FR family of models, (2) alignment and interoperability of namespaces of ISBD, FRBR, FRAD and FRSAD, (3) ICP: International Cataloguing Principles - review. Furthermore, the plan is defined in the framework of the preparation of the documentation for the revision process of the ISBD, to start in four years time after the publication of the ISBD (2011-2015).

The ISBD Strategic Plan was further discussed as part of the call for comments from the Cataloguing Section's SC, and a briefing paper of ISBD RG members' view was prepared for the August 2013 meeting at the $79^{\text {th }}$ IFLA General Conference in Singapore.

II.

Reports

\section{Projects and financial report}

As part of the priority plan for 2012 defined due to the fact that ISBD RG's project for 2012 was not approved, extra funding was secured by PC to finish the work on the ISBD Profile in $R D A$. This is the action that resulted from the Outcomes of the ISBD Review Group and ISSN Network with the JSC for Development of RDA harmonization meeting, Glasgow, UK, November 3-4, 2011, ${ }^{4}$ the project funded in 2011, Project no. D3.4.13-1/11 IFLA ISBD RG and JSC/RDA meeting on alignment and interoperability of standards. The meeting took place in Madrid, 19 and 20 September 2012, and the document was finalized for comments at the August 2013 meeting. The funds approved: 1191 Euros.

The proposed project for 2013 on ISBD Namespaces Alignments and Publication as Linked Data was approved by the PC as G3.13.2-1/13. The activities were carried on by the ISBD/XML Study Group (see the report). The work was conducted by email and skype call consultations, so no funds were spent in the first part of the year. The face to face meeting is planned for the second part of the 2013 .

\footnotetext{
${ }^{1}$ See Objectives on ISBD RG's website at: http://www.ifla.org/about-the-isbd-review-group

2 http://www.ifla.org/en/node/1959

3 http://www.ifla.org/en/node/6172

4 http://www.ifla.org/files/cataloguing/isbdrg/JSC_ISBD_ISSN_Outcomesfinal.pdf
} 


\section{ISBD/XML Study Group activities report (Françoise Leresche, Chair) ${ }^{5}$}

\section{Namespaces for the Consolidated ISBD}

The concept vocabularies were enriched with translations of preferred terms (Italian, Serbian, Chinese, Bulgarian, Latvian, and Russian).

\section{Progress Report on the Activities defined in the Work Plan for 2012-2013}

The ISBD/XML SG took part in the work on the ISBD-to-RDA mapping by preparing the mapping on the basis of the RDF declarations of the two standards in the OMR. The SG contributed comments for the drafting of the ISBD RG's discussion papers and the response to JSC (6JSC/ISBD/Discussion/1 Alignment of the ISBD element set with RDA element set - RDA, Appendix D.1, and 6JSC/ISBD/Discussion/2/JSC response/ISBD response, July 5, 2013).

The work on specialized translation guidelines for ISBD namespaces was left pending, awaiting the final version of the general guidelines on Translations of RDF representations of IFLA standards from Namespaces TG to be approved at August 2013 meeting.

The project by the UNIMARC Core Programme UNIMARC representation in $R D F$ has started and is led by G. Dunsire, M. Willer and P. Perožić. A communication of the first results will be presented at the UNIMARC session at the $79^{\text {th }}$ IFLA general conference, Singapore. The preliminary mappings between the ISBD and UNIMARC namespaces presented in the paper will be used for further work on the alignment between the two namespaces.

Discussion paper on Resource vs. WEMI entity resolution was prepared by G. Dunsire and distributed for discussion and approval at the August 2013 meeting.

A working group gathering representatives of the Bibliothèque nationale de France $(\mathrm{BnF})$ and of the ISSN International Centre (ISSN IC) developed an extension of FRBRoo, named PRESSoo and devoted to bibliographic information relating to serials and continuing resources: Version 0.1 of PRESSoo, released in March 2013 and available on the ISSN IC website: http://www.issn.org/224155-PRESSoo-model.php. Two members of the ISBD/XML SG, G. Dunsire and F. Leresche, took part in this meeting, Paris, 24 April 2013.

ABES (Agence bibliographique de l'enseignement supérieur, France) has begun to work on the publication of records from its catalogue as RDF fine-grained data, with library professionals as a target audience. They chose to use ISBD classes and properties for the bibliographic description, but faced a number of problems; the briefing paper was prepared for discussion at the August 2013 meeting.

Guidelines for use of ISBD as Linked Data, planned for 2013-2014: G. Dunsire wrote a paper on unconstrained namespaces and extending ISBD for linked data as part of a general version of the paper under preparation for the Namespaces TG. The paper was distributed for comments and discussion at the August 2013 meeting.

A number of draft mappings between elements and concepts from multiple bibliographic namespaces, including ISBD and Dublin Core Terms, have been developed during the UNIMARC namespace activity, and are being considered by the DCMI Bibliographic Metadata Task Group. The maps are available at http://wiki.dublincore.org/index.php/Maps_between_bibliographic_vocabularies.

\footnotetext{
${ }^{5}$ For detailed report see: http://www.ifla.org/node/1795\#reports
} 
G. Dunsire has reported a number of issues relevant to the ISBD revision process to the Chair of ISBD RG.

G.Dunsire has produced a diagram of mappings/alignments and related projects, inspired from the LOD cloud diagram, which shows with which value vocabularies and element sets the ISBD vocabularies for Area 0 and the ISBD element set have a partial or complete alignment table. The diagram was sent to the ISBD RG for comments and discussion at the 2013 August meeting.

\section{Meetings}

The ISBD/XML Study Group held no working meeting during this year.

The ISBD/XML SG participated in the meeting organized by the ISSN International Centre, Paris, 24 April 2013. Present: Gordon Dunsire (co-chair of DCMI Bibliographic Metadata Task Group and consultant for the ISBD/XML SG), Françoise Leresche.

Gordon Dunsire represented ISBD and other IFLA namespaces at the NISO Bibliographic Roadmap Meeting, Baltimore, USA, 15-16 Apr 2013, and at the Sixth Multilingual Web Workshop: Making the multilingual web work, Rome, Italy, 12-13 Mar 2013.

\section{Presentations at conferences}

See below.

\section{Perspectives for the ISBD/XML SG}

At the ISBD/XML SG's meeting in Helsinki on 13 August 2012, it was deemed premature to disband the SG, as long as the status of the Namespaces Task Group was not clarified, and it was therefore decided that the ISBD XML SG would be prolonged for one year, with the same objectives. During this year, further discussions and consultations were done with G. Dunsire in his capacity as the Namespaces TG chair and the consultant to the ISBD/XML SG, and with F. Leresche, as chair of the ISBD/XML SG, taking into account the SG'S objectives and remit as well as the situation of the Namespaces Task Group. The consequence is that maintaining the status quo should pertain while waiting decisions from IFLA about the status of the Namespaces Task Group.

The impact of this situation on the ISBD/XML SG, its name and its future work, will be examined and discussed at the ISBD RG and ISBD/XML SG meetings during the August 2013 meeting, and reported to the Cataloguing Section's SC.

\section{III.}

\section{ISBD Review Group activities report (Mirna Willer, Chair)}

\section{Elections}

ISBD Review Group announced the call for nominations for the three available positions to replace members whose second term ends in 2013. Four members complete their first term in 2013, and they have expressed interest in being renewed. Three nominations were received: Lynne Howarth (University of Toronto, Canada), Ricardo Santos Muñoz (Biblioteca Nacional de España), and María Violeta Bertolini (Instituto de Formación Técnica Superior No. 13, Buenos Aires, Argentina). ISBD RG forwarded these nominations for approval by the SC.

The ISBD RG wishes to thank the outgoing members for their commitment and work: Renate Gömpel (Deutsche Nationalbibliothek), Dorothy McGarry (Los Angeles, CA, USA), and Glenn Patton (OCLC, Dublin, OH, USA). 
ISBD consolidated edition online

The publishing of online ISBD edition has not been resolved. The matter is urgent because the ISBD text is prerequisite for further development of ISBD application profile, and as a consultation documents for online tools and services developments based on the ISBD namespaces.

Mappings, alignments, profiles from ISBD to other bibliographic schemas

ISBD to RDA: Glasgow meeting Outcomes:

Discussion papers and ISBD/RDA mappings and alignments were sent to the JSC, together with the further response on their comments, and the updated RDA App. D.1 ISBD Punctuation. The documents are published as $6 J S C / I S B D / D i s c u s s i o n / 1 \& 2$ The ISBD/RDA mappings and alignments are published on the ISBD RG website at: http://www.ifla.org/publications/international-standard-bibliographic-description, Documentation. Outstanding: ISBD Profile in RDA distributed for discussion at the August 2013 meeting; review of the Glasgow Outcomes, and decision on further actions to be based on the priorities of the ISBD Strategic Plan.

Other mapping activities: documents distributed for discussion and approval at the August 2013 meeting (see also ISBD/XML SG report):

ISBD unconstrained elements and extensions: briefing paper (G. Dunsire)

Resource vs WEMI entity resolution discussion paper (G. Dunsire)

Alignments between the namespaces of ISBD, other IFLA standards, and external standards (G. Dunsire)

ISBD and REICAT mapping (S. Forassiepi)

Draft survey on use of ISBD

Draft survey was prepared (A. Galeffi, J. Hostage, I. Kavčič and D. McGarry) and distributed for comments and approval at the August 2013 meeting. The survey is relevant to the revision process, and the results and their analysis is planned for distribution prior to August 2014.

Presentations and publications

M. Willer \& G. Dunsire. Bibliographic information organization in the Semantic Web, Chandos, (October) 2013

[http://www.woodheadpublishing.com/en/book.aspx?bookID=2876]

M. Willer, G. Dunsire \& P. Perožić. UNIMARC in RDF Project: namespaces and linked data, IFLA, 2013, UNIMARC Open Session, 22 Aug, (Room324/325)

G. Dunsire, M. Willer \& P. Perožić. Representation of the UNIMARC Bibliographic Data Format in Resource Description Framework, DC 2013, 5 Sep.

G. Dunsire. IFLA in RDF (+ RDA). Lightning presentation to NISO Bibliographic Roadmap Meeting, Baltimore, USA, 15-16 Apr 2013

G. Dunsire. Multilingual issues in the representation of international bibliographic standards for the Semantic Web. Presentation to Sixth Multilingual Web Workshop: Making the multilingual web work, Rome, Italy, 12-13 Mar 2013

G. Dunsire. Granularity in Library Linked Open Data. Keynote presentation at Code4Lib 2013, Chicago, USA, 12-14 Feb 2013. 
G. Dunsire. Mapping FRBR, ISBD, RDA, and other namespaces to DC for interoperability. Presentation to Kunnskapsorganisasjonsdagene 2013, Oslo, Norway, 7-8 Feb 2013

M. Willer. ISBD: information on the activities so far, and the reasons for attending to it... SCATNews No 39, June 2013

Cataloguing \& Classification Quarterly issued the call for papers for a special issue which will be devoted to the evaluation and adoption of ISBD: International Standard Bibliographic Description, consolidated edition, published in 2011; guest editors are M. Willer, L. Howarth and J. Hostage. Planned publishing date is 2014.

Respectfully submitted by

Mirna Willer

ISBD Review Group, Chair

7 August 2013 


\section{APPENDIX III: ISBD Strategy}

Within the next year it will be time to consider a review of the ISBD.

Before starting a traditional review we think the time has come for the CATS SC to consider the future role of the ISBD.

The CATS SC has the responsibility of setting a strategy for the ISBD.

This paper should be seen as an inspiration for the CATS SC in order to raise some questions. We suggest a preliminary discussion at the 2013 SC meeting and that we then get back to the subject at next year's meeting. In between the meetings a discussion amongst the SC members and members of ISBD RG would be most welcome as well as we would encourage other groups and institutions to express their position. We need to share arguments and considerations, before the SC makes a decision about the strategy .

\section{Current strategic plan}

Our current strategic plan states as follows about the ISBD:

\section{Continue ISBD revision}

- 3.1. Maintain and develop the ISBD content standard; Assess any amendments to be recommended by the Review Group.

- 3.2. Develop mapping between ISBD and the FRBR family of conceptual models in the RDF environment to inform the further development of ISBD itself, and increase the understanding of the relations between ISBD and FRBR.

- 3.3. Provide leadership in encouraging harmonization of existing cataloguing rules with the ISBD through communication with rule-making bodies internationally by forming liaison relationships between each rule-making body and the ISBD Review Group.

- 3.4. Develop and maintain representations of the ISBD that are compatible with current electronic and semantic web environments for resource discovery and the management of metadata for use in digital and non-digital catalogues.

- 3.5. Maintain liaisons with the Permanent UNIMARC Committee, the ISSN Network, and the International Association of Musical Libraries, Archives and Documentation Centres (IAML), with other IFLA units, and with other relevant groups to assure widespread use of the ISBD as a metadata content scheme.

- 3.6. Encourage translations of the consolidated ISBD.

- 3.7. Develop training material centred on definitions, structure and the use of ISBD for rule making bodies and in general for teachers, cataloguers, etc.

\section{Statements/Questions to consider}

- Has the time come when developing and maintaining a standard such as ISBD simply can't be done on a voluntary basis while still securing truly international involvement?

- Even though RDA isn't an IFLA product it is hard to ignore that RDA most likely will be considered a de-facto-standard in large parts of the world.

- Will the countries using RDA put all their efforts on developing rules into RDA and not be able to contribute to ISBD? Perhaps consider ISBD less important? 
- If RDA and ISBD continue their separate development and make efforts to harmonize the content, who benefits from having two standards describing the same things and often involving the same people?

- What about the obligation to countries who have based their development and trust in IFLA continuing to provide guidelines through the ISBD?

- What about countries preferring other codes than RDA?

- What about the social obligation to countries where they can't afford RDA? (on the other hand: can they afford to implement ISBD as it is for now?)

- IFLA is the natural and truly democratic place for international cooperation: but the form the work takes must be adjusted to what is feasible. Could the ISBD evolve to a shorter, more principle-based, simple and basic standard that would be able to be incorporated into other codes but also could be used by itself by countries with no possibility to implement a more sophisticated code?

Miriam and Hanne 


\title{
APPENDIX IV: ISBD Strategy: ISBD RG comments 1 (2)
}

\author{
e-mail to Hanne H. Hansen, 7 August, 2013
}

Dear Hanne and colleagues,

ISBD Review Group had extensive and very fruitful discussions on the questions you put regarding ISBD strategy and further development.

The majority of the members agree with the status of the ISBD as the IFLA bibliographic standard crutial to the functioningof the Universal Bibliographic Control, and its relation to the RDA, as one of the cataloguing rules. This view was presented in the document by Françoise Leresche, and adopted by that majority.

There were two other opinions, however, that do not share such a view, and that point to the fact that the today's world has changed so much, and that economic and other factors will influence the adoption of one cataloguing code - RDA, as they do not see viable that national cataloguing bodies would consider developing particular national cataloguing rules. ISBD as an IFLA standard is seen either only as a display format, or, vaguely, as some kind of necessity related to FRBR.

There is still another opinion, expressed by the previous chair of the ISBD RG, Elena Escolano Rodriguez. Elena endorses F. Leresche's view, but she reminds of the discussions on IFLA's role in bibliographic Standards document on reinstating the UBC going on in 2010 in all Division IV sections.

Elena additionally reminds us all of the activities related to ISBD and UBC based on the IFLA Strategic plan, 2010-2015, where the third mission still reads:

" - drives high standards in library and information services and professional practice;" And as Goals reads: "To advance the profession through the development of standards and the promotion of specialised knowledge within the professional practice..."

She notes that: "According with this high statement in the Strategic Plan the standard of IFLA, by antonomasia, can't be questioned at least until 2015."

Additionally, Elena raises the questions whether UNIMARC Core Programme has received such a question, and what is the status and what activities done by the Committee on Standards in which bibliographic standards are represented. She recommends joint discussions and response.

To this, I would add that joint discussions would be needed lead by the Cataloguing Section with Bibliography Section, National Libraries Section, and Information and Technology with their Semantic Web SIG. Perhaps other interested sections could be attracted outside the Division III, like rare Books and Manuscripts Section. 
The results from the Survey on the ISBD use that ISBD RG plans for 2013/2014, with results and analysis prepared for the ISBD RG meeting in 2014, will be important input to the planned discussions. 


\section{APPENDIX V: ISBD Strategy: ISBD RG comments 2 (2)}

\section{Role and function of Cataloguing Section}

\section{Action Plan, 2011/2013}

\section{Mission}

The Cataloguing Section of IFLA strives to be the leader in international developments in cataloguing theory, activities, and standards development. The Section analyses the principles and functions of cataloguing activities for all types of materials and media, including both bibliographic and authority information, for the benefit of all kinds of users. The Section proposes and develops cataloguing rules, guidelines, and standards for bibliographic information, taking into account the developing electronic and networked environment in order to promote universal access to and exchange of bibliographic and authority information.

Standardization of cataloguing at the international level so as to enable data exchange and derivation across national borders (at the core of UBC)

Hence:

- the International Cataloguing Principles

- the ISBD

- the rules for constructing access points (corporate headings), and, as an application of the principle according to which national forms for personal names and work titles should be preferred, reference documents such as Names of Persons and Anonymous Classics

Even the FRBR model resulted from an effort towards the simplification of cataloguing rules. It was developed as part of the standardization endeavour, with direct consequences for the ISBD (distinction first between mandatory, conditional, and optional elements, later on between mandatory and optional elements).

That role as a standards body lies at the heart of the Section's activities. All of its other activities are related to it, and it is useful for other sections as well (most notably, the Bibliography Section).

There has been a trend, within the Section SC, for several years, towards the abandonment of standardization activities, which are handed over to other actors, outside IFLA:

- transferal of Names of Persons to VIAF or ISNI

- end of work on the Anonymous Classics

ISBD does not escape that trend, and the publication of RDA might be the pretext for the abandonment of cataloguing standardization to the benefit of a dominant cataloguing code.

I think that this trend is most alarming, because it amounts to giving up IFLA's role as an international standards body in the field of cataloguing. 
What would be the purpose of the Cataloguing Section, were it deprived of that role? Ought it just to survey global cataloguing practices, without being able to direct them towards greater interoperability and an openness aiming at facilitating exchanges?

In the context of digital information and the Web of data, cataloguing standardization has to evolve as it is facing novel situations and challenges. I think that we are at the verge of a transformation of bibliographic information which will prove as radical as in the 1960s-70s when the ISBD and ISBD-related standards were being developed.

The Cataloguing Section should be the place for truly international reflections on today's cataloguing, basing on FRBR and the Web of data, and taking its specific agenda into account:

- thinking about international exchanges among national bibliographies (UBC): providing normative tools for national bibliographies and expressing these normative tools as cataloguing rules in both large and small libraries (RDA is one such cataloguing code, it was designed so as to meet first the needs of local cataloguing, and only then the needs of bibliographic interchange);

- taking into account all countries (with their various levels of development, various cultures, etc.)

This implies an in-depth revision of the ISBD (as demonstrated by the work done on alignments) so that it can be adapted to the current environment, rather than abandoned and substituted with a code that was developed outside IFLA, with no genuine international representation.

\section{Questions posed in the SC's discussion paper}

Statements/Questions to consider:

- Has the time come when developing and maintaining a standard such as ISBD simply can't be done on a voluntary basis while still securing truly international involvement? It seems to me that IFLA is the place that best warrants a genuine international representation, with experts from potentially every country, and any institution.

The voluntary basis is a requisite for international standardization; it also warrants neutrality. The Section has many members (including corresponding members), it is a pool of competencies that is insufficiently exploited.

- Even though RDA isn't an IFLA product it is hard to ignore that RDA most likely will be considered a de-facto-standard in large parts of the world.

So far, RDA has just the same area of influence as AACR.

It is a cataloguing code that partially refers to IFLA: it does so when it comes to IPC, FRBR/FRAD, but it regards ISBD only as a displaying format (in the continuation of AACR that only took into account the $\operatorname{ISBD}(G)$ schema, not the rules properly said).

Normally, the ISBD is a normative general framework that defines the rules for bibliographic description within the UBC framework. Those rules can then be adapted at the national level as cataloguing codes. RDA is just one such code, even though it is supranational. It is important to keep the ISBD as the reference normative document when it comes to bibliographic description, at a higher level than any particular code.

- Will the countries using RDA put all their efforts on developing rules into RDA and not be able to contribute to ISBD? Perhaps consider ISBD less important?

This is a risk, and a prioritizing issue at the national level. 
For instance, France is currently working on three issues: ISBD evolution, RDA evolution (proposals transmitted through EURIG), and revision of national rules so as to enable a FRBRized catalogue (as long as RDA has not evolved satisfactorily).

HOWEVER, if the ISBD is reaffirmed as the ONLY international reference standard, at a higher level than its various declinations as local codes (such as RDA), the JSC would better keep an eye on the evolution of IBSD, and even participate in it.

- If RDA and ISBD continue their separate development and make efforts to harmonize the content, who benefits from having two standards describing the same things and often involving the same people?

Once again, the ISBD is the international reference standard. It hovers at a higher level than national, linguistic, and cultural choices or preferences. The ISBD is needed to achieve that goal.

Besides, the ISBD is a bibliographic standard, not a cataloguing code.

RDA is a cataloguing code. It is being developed by a specific community, and will always tend to privilege that community's needs. It is delusive to think that RDA, the way it is currently being developed, could evolve towards a genuine international standard that would meet everybody's needs.

- What about the obligation to countries who have based their development and trust in IFLA continuing to provide guidelines through the ISBD?

A huge responsibility weighs on IFLA. IFLA is the international reference and must continue to provide the reference framework for the cataloguing of resources.

Besides, the ISBD is an open standard, anybody has access to it. It also is a crucial item for less-developed countries that can use it as a reference for the definition of their national rules, or even directly as a cataloguing code (although the consolidated ISBD has turned more generic, making such a utilization of the ISBD more difficult).

- What about countries preferring other codes than RDA?

If such codes refer to the ISBD, this is not an issue.

The ISBD is the warrant for interoperability between national codes.

- What about the social obligation to countries where they can't afford RDA? (on the other hand: can they afford to implement ISBD as it is for now?)

A number of countries do so (and have been doing so for quite some time): they use ISBD directly as a cataloguing standard.

- IFLA is the natural and truly democratic place for international cooperation: but the form the work takes must be adjusted to what is feasible. Could the ISBD evolve to a shorter, more principle-based, simple and basic standard that would be able to be incorporated into other codes but also could be used by itself by countries with no possibility to implement a more sophisticated code?

In my opinion, there is an internal contradiction in this proposal.

If the ISBD is to be used directly by countries that cannot afford to adopt a more sophisticated (and, more importantly, more expensive, in terms of subscription) code, it definitely cannot be simplified and made even more generic.

The cases encountered when cataloguing must be addressed in a more detailed way, along with the recommended solution. That is what a cataloguing code is supposed to do.

It could be envisioned to split the ISBD into two distinct parts: 
- the international reference standard, at a rather generic level;

- and an implementation handbook that elaborates on the main practical cases encountered in cataloguing and provides many examples, for use by countries that cannot afford to adopt a more sophisticated code or to develop a national code based on the ISBD.

As to human resources and feasibility issues, let me remind that the Cataloguing Section counts many members, and always arouses much interest at the time of elections. In the same vein, the ISBD RG counts 12 members, only a half of which are really active. If all 12 members of the ISBD RG were more strenuous, much would be achieved indeed!

Françoise Leresche

Member of the ISBD RG

Head of the Standards and Models Unit

Bibliographic and Digital Information Department

National Library of France 


\title{
APPENDIX VI: ICP revision: 2012-2013 activity
}

\begin{abstract}
Report on IFLA Cataloguing Section Strategic plan section 1.3 "Modify the Statement of International Cataloguing Principles (ICP) as necessary for today's rapidly evolving environment based on regular evaluation of the principles. The first review is scheduled for 2014 or sooner as deemed necessary. The first evaluation will take place in 2011/2012 preparing a recommendation for the SC on whether a review is needed or not by the 2012 meetings."
\end{abstract}

\section{Background}

The ICP took 6 years from the first drafts in 2003 until the publication in 2009. During Cataloguing Section meetings in Helsinki it was decided that "The ICP must be general, so it does not have to be updated too often. There is ongoing work on aligning the IFLA standards mentioned in the ICP; should the review work start now, it must follow this alignment process closely." 6

The group appointed for the task thinks that it's necessary to define preliminarily the path this revision should follow since it could lead to different results.

\section{Rationale}

The group has identified two hypotheses.

The first hypothesis is considering that the ICP structure is still good, with just updating all the topics that since 2009 have seen some kind of evolution.

Among the topics to be updated:

1. "This statement builds on the great cataloguing traditions of the world, and also on the conceptual model in the IFLA Functional Requirements for Bibliographic Records (FRBR)."

The FR family is currently under revision. Probably it could be useful to wait for the harmonization among FRBR, FRAD and FRSAD in order to incorporate the results into ICP;

2. "It is hoped this statement will increase the international sharing of bibliographic and authority data and guide cataloguing rule makers in their efforts to develop an international cataloguing code".

The objective of an international cataloguing code is not, as far as we know, in the intentions of any institution. Furthermore in Helsinki the Cataloguing Section decided, as in the meeting Report, "7.2 CATS strategic plan, 1.4 (Strategy on international cataloguing code): Hansen and Säfström presented a discussion paper on the subject (See Appendix IV). It was concluded that the Cataloguing Section should not aim to form an international cataloguing code. The Cataloguing Section should, however, continue to take a leadership and partnership role in international cataloguing work. CatSec products such as the ICP, the FR family and the ISBD, which includes basic elements for descriptive cataloguing, form the backbone of evolving cataloguing codes throughout the world. It was decided that Section 1.4 in the strategic plan should be deleted";

3. The concept of the catalogue is quite traditional;

\footnotetext{
6 http://www.ifla.org/files/assets/cataloguing/reports/meeting_2012.pdf

${ }^{7} \mathrm{Ib}$.
} 
4. In Scope "They aim to provide a consistent approach to descriptive and subject cataloguing of bibliographic resources of all kinds." Subject cataloging is neglected in ICP;

5. Other principles could be added to answer new needs. Principles such as Openness and Interoperability of data/information, for example, could fulfill the features of open data repositories.

The second hypothesis is based on the fact that revision of ICP should not be just an update but involve a deep change in the structure of the document. The present text comprehends, in addition to the principles, many paragraphs not relating to these principles. It should be necessary to improve the coherence of ICP, defining, above all, its scope and objectives.

If ICP should be just principles, at least points 3. Entities, Attributes, and Relationships, 5. Bibliographic Description, 6. Access Points, and 7. Foundations for Search Capabilities should be deleted. The ICP could be, in this case, a very short statement, just presenting an introduction and a list and explanation of principles. The remaining parts could be moved into a separate document to maintain the agreements reached during the ICP process.

If ICP is not just a statement about principles, at least the title should be changed in order to avoid misunderstandings.

Other issues to be considered, in any case, are:

1. Is ICP only for libraries or for libraries, archives and museums?

If it is only for libraries (since no other communities have accepted them), then it is consistent to include FRBR, and also ISBD.

If ICP is not only for libraries, then FRBR has to be moved to a footnote and other contexts have to be kept in consideration;

2. ICP are principles of cataloging, not of the catalog;

3. The concept of "convenience", the highest principle, could be defined and explained more in depth.

The group wants to submit these hypotheses to the Cataloging Section Standing Committee in order to identify more precisely the revision to be carried on.

August, $7^{\text {th }} 2013$

Respectfully submitted by:

Elena Escolano Rodriguez, Agnese Galeffi (Chair), Dorothy McGarry, David Reser. 


\section{APPENDIX VII: Names of persons: report 2013}

\section{What is Names of Persons?}

It is a collection of the rules followed by every single country for the construction of the preferred form of the name of that country's nationals. Its purpose is to provide cataloguers with guidelines for the construction of the preferred access point for authors, in conformance with the Statement of International Cataloguing Principles (ICP).

\section{ICP}

\subsubsection{Form of Name for Persons}

When the name of a person consists of several words, the choice of first word for the authorized access point should follow conventions of the country and language most associated with that person, as found in manifestations or reference sources.

Names of Persons is a useful tool for ensuring that a person's name will be treated consistently at international level.

Names of Persons is an international standardization effort - and as such it should be maintained by an international institution like IFLA. It is part of IFLA's mission and IFLA has the legitimacy to undertake that responsibility.

Two issues are related to the work on Names of Persons:

- The collecting of information and the updating of the pages devoted to each country; while such countries that have a bibliographic tradition are responsive and provide information for the pages devoted to them, some other countries are difficult to get in touch with and/or are not sensitive to this issue, and do not take the time required to document (or indeed define) their policy.

- The release of information for it to be available to professionals.

Judy Kuhagen did a huge work updating extant pages. Much information was gathered from several countries. That work should be released without awaiting the countries that did not respond or for which no contact person was identified. Such a release might have a boosting effect on 'slower' countries.

As to the releasing of information, it seems best to devote part of the Cataloguing Section's Web site to that, in the same way as a page of it is already devoted to the International Cataloguing Principles and all the translations in which they are available.

For the management of the Web pages devoted to Names of Persons, we propose the creation of a form to be filled in by the various countries in order to document their policy, a page where they can upload the resulting files with the date of update. The Cataloguing Section might benefit from getting in touch with the Bibliography Section, whose National Bibliographic Register is managed in that way, and from drawing inspiration from the Bibliography Section's method and organization.

Additionally, we could lean on members and corresponding members of the Cataloguing Section's Standing Committee - which amounts to a fairly large representation of the various continents - to sensitize countries in their geographical area to filling in or updating the page devoted to them.

Regarding the proposal to devote the publication (and follow-up?) of Names of Persons to other institutions: 
VIAF (Virtual International Authority File), reply received from Tom Hickey, who is very doubtful that OCLC and VIAF would be of any more success in bringing this project forward. Françoise Leresche talked about it with Vincent Boulet and he thinks, too, that it is not up to VIAF to manage Names of Persons.

VIAF is not a standards body. It is managed by OCLC and is therefore not even affiliated to an international institution such as IFLA. As a consequence, it does not have the legitimacy to manage reference documents in cataloguing.

VIAF gathers input from users who are expected to apply Names of Persons as a reference tool when creating authority records for personal names. VIAF is therefore entitled to:

- $\quad$ promote the use of IFLA rules (International Cataloguing Principles, Names of Persons),

- encourage references to Names of Persons when selecting the preferred form of a personal name in order to construct the authorized access point,

- invite new VIAF partners to take part in the collecting of national rules by creating or updating the page devoted to their country,

but it is not the role of VIAF to manage Names of Persons.

ISNI (International Standard Name Identifier) is no solution either, and the ISNI Registration Authority is not willing to play that role.

ISNI is but an identifier. The purpose of ISNI is to uniquely identify the entities represented in the Register; as a consequence, the names of those entities are but metadata (albeit crucial ones) that support the identification. But the standardization of the names of the identified entities does not pertain to ISNI.

As a matter of fact, many forms of names, structured according to different traditions and conventions, coexist in the ISNI Register, as ISNI does not serve exclusively the library community; it is a linking identifier between various domains of cultural industries.

ISNI relies on data created by libraries, which is an advantage for ISNI which exploits genuine expertise in the field of authority data, but this does not mean that ISNI will be able to impose the standardization achieved by libraries on all parties.

On the same pattern as VIAF, ISNI just reflects cataloguing rules in its data. It is not an actor of the standardization of the metadata associated with the identifier. 


\section{APPENDIX VIII: Report from ALA CC:DA, ALA Midwinter Conference 2013}

Report on the American Library Association's Committee on Cataloging: Description and Access, ALA Midwinter Conference, Seattle, Washington, USA, 2013 January 26 and 28

Submitted to the Standing Committee of the IFLA Cataloguing Section by the IFLA Cataloguing Section Liaison to ALA CC:DA

The American Library Association's Committee on Cataloging: Description and Access (CC:DA) met at the ALA Midwinter Conference in Seattle, Washington, USA, on Saturday 2013 January 26, 1:00-5:30 P.M.; and Monday 2013 January 28, 8:30-11:30 A.M.

New CC:DA Chair Mr. Peter Rolla (Harvard University) reported on motions and other actions taken by CC:DA between July and October 2012 (http://alcts.ala.org/ccdablog/wpcontent/uploads/2013/02/chair201301.pdf).

New Library of Congress (LC) Representative Mr. David Reser reported on activities and news from LC (http://alcts.ala.org/ccdablog/wp-content/uploads/2013/02/lc201301.pdf). Some of the highlights of his report:

- With the retirement of Ms. Barbara Tillett as Chief of the Policy and Standards Division in November 2012, Mr. Tom Yee became acting chief. Mr. Reser became LC Representative to the Joint Steering Committee (JSC) in December 2012, with Ms. Kate James as his backup. Ms. Tillett will continue to serve as JSC Chair through December 2013.

- LC published "Bibliographic Framework as a Web of Data: Linked Data Model and Supporting Services" (http://www.loc.gov/marc/transition/news/bibframe112312.html) in November 2012. This high-level model was developed by Mr. Eric Miller of Zepheira.

- In the October 2012 release of the Resource Description and Access (RDA) Toolkit, Library of Congress Policy Statements became Library of Congress-Program for Cooperative Cataloging Policy Statements (LC-PCC PS, or PS for short). This reflects the fact that the PSs represent a collaborative set of statements for both the Library of Congress and the PCC.

- The U.S. RDA Test Coordinating Committee issued its final quarterly update on January 4, 2013 (http://www.loc.gov/aba/rda/pdf/RDA_updates_04jan13.pdf), finding that activities related to RDA preparation and implementation had progressed sufficiently for a joint implementation of RDA in 2013.

- RDA training of LC staff should be completed by March 31, 2013. All LC training materials have been made freely available on the Catalogers Learning Workshop Website at http://www.loc.gov/catworkshop/RDA\%20training\%20materials/index.html. 
- Revisions of the "Subject Headings Manual" and the "Classification and Shelflisting Manual" in light of RDA are underway.

- During 2012, seven new and ten updated ALA-LC Romanization tables were approved. All current tables are available at http://www.loc.gov/catdir/cpso/roman.html.

The ALA Representative to the JSC, Mr. John Attig (Pennsylvania State University), submitted his report (http://alcts.ala.org/ccdablog/wp-content/uploads/2013/01/jsc1301.pdf) on the JSC meeting in Chicago, November 5-9, 2012. He also reported that the December 2012 release of the RDA Toolkit included Chapters 6, 9, 10, and 11 reworded by Ms. Chris Oliver (McGill University). Next will be Chapters 2 and 3, with all of the remaining chapters in progress. As changes are made to RDA, the RDA vocabulary and element sets registry is being kept up-to-date. After six years in the position, Mr. Attig will end his term as ALA Representative to the JSC at the end of the ALA Annual Conference in Chicago, June 2013. The process to replace him is underway. The JSC itself is also revising its structure so that the Chair will no longer also be the representative of a constituency. The new Chair will be one of the current JSC members, but a new person will be chosen to represent that person's constituency. A full account of the proposed JSC changes can be found at http://alcts.ala.org/ccdablog/wp-content/uploads/2013/01/jsc1301a.pdf.

The Task Force on Relationship Designators in RDA Appendix K reported on its work to date (http://alcts.ala.org/ccdablog/wp-content/uploads/2013/01/TFappendixK201301.pdf) and aims to have completed its work by ALA Annual 2013. In discussions, it was decided to restore to the list the gender-neutral terms (such as child and parent) that had previously been removed. Mr. Dunsire is studying the desirability of making each of the designators into verbal phrases (for instance, "is [blank] of") in order to clarify the direction of the relationship.

The Task Force on Instructions on Recording Relationships submitted its paper (http://alcts.ala.org/ccdablog/wp-content/uploads/2013/01/TFrelationships201301.pdf) attempting to clarify the distinctions between structured and unstructured descriptions and to come up with a principle-based explanation of the proper relationships of contents notes to Works and to Manifestations.

The report (http://alcts.ala.org/ccdablog/wp-content/uploads/2013/01/tfchicago4.pdf) of the Task Force to Investigate Changes Affecting RDA in the Chicago Manual of Style, 16th edition, was discussed in the absence of its chair (who encountered travel problems). Discussion concentrated on those issues with a high impact, generally affecting Authority records. Mr. Gary Strawn (Northwestern University) ran some preliminary tests to measure the impact of various hyphenation issues, finding that there might be problems with some programmatic conversions because of capitalization differences among languages.

Ms. Kathy Glennan (University of Maryland) reported on the activities of the Program for Cooperative Cataloging (PCC) (http://alcts.ala.org/ccdablog/wpcontent/uploads/2013/01/pcc201301.pdf). Among her points:

- Approval of the "PCC RDA BIBCO Standard Record (BSR) Metadata Application Profile" (http://www.loc.gov/aba/pcc/scs/documents/PCC-RDA-BSR.pdf), which has been expanded to include all bibliographic formats.

- Approval of the "Provider-Neutral E-Resource MARC Record Guide: P-N/RDA Version," now including serials and integrating resources (http://www.loc.gov/aba/pcc/scs/documents/PN-RDA-Combined.docx). 
- Recommendations from the "Report of the PCC Access Points for Expressions Task Group"

(http://www.loc.gov/aba/pcc/rda/RDA\%20Task\%20groups\%20and\%20charges/PCCE xpressionTGFinalReport.docx) are being incorporated into the LC-PCC PSs by the PCC Standing Committee on Standards.

- The "Report of the PCC Post-Implementation Hybrid Bibliographic Records Guidelines Task Group"

(http://www.loc.gov/aba/pcc/rda/RDA\%20Task\%20groups\%20and\%20charges/PCCHybrid-Bib-Rec-Guidelines-TG-Report.docx) advocated the continued co-existence of hybrid records, the use of machine conversions where feasible, and local decisions about manual recataloging where necessary.

- The PCC Policy Committee followed up on the "PCC Relationship Designator Guidelines Task Group Report" (http://www.loc.gov/aba/pcc/rda/RDA\%20Task\%20groups\%20and\%20charges/PCCRelat-Desig-TG-report.rtf) with the decision to add designators to both AACR2 and RDA records programmatically where needed.

Ms. Tracey Snyder (Cornell University) reported on the evolution of the Music Library Association (MLA) Bibliographic Control Committee (BCC) RDA Music Revisions Facilitation Task Force into the JSC's RDA Music Joint Working Group. By bringing together music specialists from LC, MLA, the Canadian Association of Music Libraries (CAML), and eventually, the European RDA Interest Group (EURIG), the JSC hopes to assure that music-related RDA proposals are coordinated and developed with the proper expertise. Although proposals will be submitted directly to the JSC, CC:DA will continue to have the opportunity to comment on them, as they do with proposals from other non-ALA constituencies. There was some concern that this JSC move could inspire other special constituencies to start to bypass the CC:DA process.

CC:DA Webmaster Ms. Melanie Polutta (LC) introduced the new official CC:DA Web site, which is the CC:DA Blog page at http://alcts.ala.org/ccdablog/. The former ALA site (http://www.libraries.psu.edu/tas/jca/ccda/index.html), covering 1995-2012, is now frozen. RDA Conference Forums and Task Force head Ms. June Abbas (University of Oklahoma) reported on the various RDA programs held at ALA Annual 2012 in Anaheim, California. A preconference on "RDA: Back to the Basics" is planned for ALA Annual 2013 in Chicago, as well a an standard "RDA Update Forum" and a session on strategies for implementation. ALA Publishing Services' Mr. Troy Linker noted several changes to the RDA Toolkit, including: the renaming of the LC-PCC PSs, the new ability to toggle links to the PSs on and off; the open availability of the authoritative mappings, so that access no longer requires a Toolkit subscription; the new ability to share workflows either locally or globally. The update schedule for the Toolkit has been the second Tuesday of each even-numbered month, but the scheduled update for February 2013 has been postponed, tentatively until April 21013. This postponement includes: RDA Toolkit Multilingual interface, French and German RDA translations, RDA Fast-track changes, RDA Reworded chapters, and LC-PCC PS changes. As soon as the rewording of all of the remaining RDA chapters is completed and reviewed by the JSC, a new print compilation of RDA will be released, tentatively in mid-2013, and annually thereafter. A concise version with the working title of "Essential RDA," including base and Core instructions, will later be made available in print, as an e-book, and in the 
Toolkit. An update to the MARC mapping is complete and approved, but can't be incorporated into the Toolkit because of the updating delays. ALA Publishing is looking for a means by which to make this available in the meantime.

MARBI Liaison Mr. John Myers (Union College) reported on MARBI actions. Because I was able to attend one of the two MARBI meetings, I have included additional details on the discussions for which I was present.

- MARC Proposal No. 2013-01 "Identifying Titles Related to the Entity Represented by the Authority Record in the MARC 21 Authority Format" (http://www.loc.gov/marc/marbi/2013/2013-01.html): Presented by Mr. Strawn, this proposal puts forth two new Authority fields, 672 (Titles Related to the Entity Represented by the Authority Record) and 673 (Titles Not Related to the Entity Represented by the Authority Record), to make titles related to the authorized entity machine-actionable. The proposal was simplified from earlier iterations in proposing the fewest subfields to serve the stated purpose. The proposal passed with the following alterations:

○ In the case of both proposed fields, the "Field Definition and Scope" was edited to add field 111 in the first sentence.

○ In the case of both proposed fields, the subfield $\$$ a was renamed to "Title proper," meant to include title subfields $\$ a, \$ n$, and $\$ p$.

- Subfield $\$ f(N R)$ for "Date" was added to field 673, with the clarification in both fields that the "Date" was whatever was found in the source.

- MARC Proposal No. 2013-02 "New Fields to Accommodate Authority Records for Medium of Performance Vocabulary for Music in the MARC 21 Authority Format" (http://www.loc.gov/marc/marbi/2013/2013-02.html): Proposes a set of Authority X62 fields for the controlled vocabulary currently under development as the "Library of Congress Medium of Performance Thesaurus for Music “(LCMPT). Approved.

- MARC Proposal No. 2013-03 "Making Field 250 Repeatable in the MARC 21 Bibliographic Format" (http://www.loc.gov/marc/marbi/2013/2013-03.html): Proposed making field 250 repeatable for multiple edition statements, in particular to accommodate "Musical Presentation Statements" heretofore coded as MARC 254. Approved.

- MARC Proposal No. 2013-04 "Defining New Code for Score in Field 008/20 (Format of music) in the MARC 21 Bibliographic Format" (http://www.loc.gov/marc/marbi/2013/2013-04.html): Because of the broader definition of "score" in RDA, MLA requested that several of the existing MARC codes for "Format of Music" be redefined and that a new code "l" for "score" be added. Approved, pending further work on the code definitions.

- MARC Proposal No. 2013-05 "Defining New Field 385 for Audience Characteristics in the MARC 21 Bibliographic and Authority Formats" 
(http://www.loc.gov/marc/marbi/2013/2013-05.html): So as to accommodate audience characteristics terms from the "Library of Congress Genre/Form Terms for Library and Archival Materials" (LCGFT), new field 385 is proposed. Approved, with changes including the elimination of subfield \$u (Uniform Resource Identifier) and the addition of subfield $\$ \mathrm{n}$ for codes to correspond to subfield $\$ \mathrm{~m}$ for the "Demographic Group Designator."

- MARC Proposal No. 2013-06 "Defining New Field 386 for Creator/Contributor Group Categorizations of Works, Expressions, and Persons in the MARC 21 Bibliographic and Authority Formats" (http://www.loc.gov/marc/marbi/2013/201306.html): So as to accommodate group category terms for creators and contributors from LCGFT, new field 386 is proposed. Approved, with changes similar to those made for Proposal No. 2013-05, the elimination of the field's use for name entities, and some other minor work.

- MARC Proposal No. 2013-07 “Defining Encoding Elements to Record Chronological Categories and Dates of Works and Expressions in the MARC 21 Bibliographic and Authority Formats" (http://www.loc.gov/marc/marbi/2013/2013-07.html): So as to accommodate chronological aspects of entities described, new subfields for Bibliographic and Authority fields 046 and new First Indicator values for the Bibliographic 648 are proposed. Approved, pending further development of an analogous Authority 648 field and some additional work.

- MARC Discussion Paper No. 2013-DP01 "Identifying Records from National Bibliographies in MARC 21 Bibliographic Format" (http://www.loc.gov/marc/marbi/2013/2013-dp01.html): Presented by Mr. Ted Fons (OCLC), this paper presented options for identifying Bibliographic records from national bibliographies. MARBI preferred the use of field 042 (Authentication Code). No further MARBI action is needed. OCLC will apply for any necessary new codes.

- MARC Discussion Paper No. 2013-DP02 "Defining Subfields for Qualifiers to Standard Identifiers in the MARC 21 Bibliographic, Authority, and Holdings Formats" (http://www.loc.gov/marc/marbi/2013/2013-dp02.html): This paper was thought to be analogous to the recent addition of subfield $\$ q$ for "Qualifying Information" to field 028 , but generated considerably more controversy, especially in the continuing resources community. Ms. Regina Reynolds (LC) noted that neither CONSER nor the ISSN International Center allows repeatable 022 fields (in spite of MARC 21), instead putting ISSNs for other versions in field 776. The use of 022 subfield \$y has become messy as the repository of much more than just incorrect ISSNs. This paper will likely come back as a proposal, but limited to fields 020, 024, and 027 , with 015 being added. The paper is trying to solve an existing problem of qualifying data being forced into a subfield in which it doesn't belong. It does not intend to exacerbate any problems with the 022 field. 
- MARC Discussion Paper No. 2013-DP03 "Defining a Control Subfield \$7 in the Series Added Entry Fields, for the Type and the Bibliographic Level of the Related Bibliographic Record” (http://www.loc.gov/marc/marbi/2013/2013-dp03.html): Presenter Mr. Reinhold Heuvelmann (Deutsche Nationalbibliothek) clarified that the Germans use MARC 21 only as an exchange format, not as a cataloging format. The data proposed for this application of subfield $\$ 7$ was admitted to be redundant of data in the linked record, but in German systems, the linked record may not yet be present. It was determined that only positions /2 (Type of Record) and /3 (Bibliographic Level from Leader/07 of Related Record) would be needed. Because the subfield $\$ 7$ defined in field 533 already deviates from the standard subfield $\$ 7$, there were no objections to another application of subfield $\$ 7$ deviating from the standard. This discussion paper will return as a proposal.

- MARC Discussion Paper No. 2013-DP04 "Separating the Type of Related Entity from the RDA Relationship Designator in MARC 21 Bibliographic Format Linking Entry Fields" (http://www.loc.gov/marc/marbi/2013/2013-dp04.html): Mr. Bill Leonard (Library and Archives Canada) presented this paper intended to devise a manner of "hiding" the parenthetical qualifiers for relationship designators; this has been a common objection to RDA among its detractors. Mr. Attig pointed out that the JSC is trying to come up with a general solution to relationships, including looking at display issues, making sure that the designators are unambiguous, and investigating the possibility of a machine-actionable relationship between subfields $\$ 4$ and $\$ \mathrm{i}$. He also reported that Mr. Gordon Dunsire (CILIP) agrees with the direction of this paper, that it is necessary to have an explicit manner to record display text. This will return as a proposal.

In addition, Mr. Myers talked a bit about the demise of MARBI following the meetings at ALA Annual in Chicago, June 2013. LC's Ms. Sally McCallum noted that the work of the MARC Advisory Committee, which has long met conjointly with MARBI, would continue, and that it would welcome continued assistance in the future development of MARC and its successor. CC:DA will name a liaison to the new Metadata Standards Committee. Exactly how everything will eventually be formulated and interrelated remains in flux.

Ms. Deborah Fritz of The MARC of Quality (TMQ) presented a demonstration of "RDA in Many Metadata Formats" (RIMMF) (http://www.marcofquality.com/rimmf), which was developed starting in 2010 as a teaching and visualization tool outside of the context of MARC and other familiar metadata structures. According to LC, RIMMF also meets the requirements for a prototype RDA input form. It is not intended to be a cataloging tool, per se, but instead helps catalogers understand and apply the new decision-making processes that RDA demands. RDA has the potential to lead to the development of better cataloging software and the creation of better discovery tools. RIMMF reveals the relationships built into RDA, showing clearly how RDA differs from AACR and how RDA may be much more simple and intuitive once divorced from MARC. RIMMF also makes clear the new mindset of data elements instead of bibliographic records, "forcing" the distinctions among Work, Expression, and Manifestation that MARC cannot manage. It will also help expose problems within RDA and its structure. To that end, Ms. Fritz submitted to Mr. Attig a set of issues and questions about RDA that have arisen in the process of developing RIMMF 
(http://alcts.ala.org/ccdablog/wp-content/uploads/2013/01/fritz201301.pdf). It was Mr Attig's feeling that none of the issues raised would require large efforts to deal with, but that he and Ms. Fritz would work together on some proposals. He also suggested that some of the issues could be resolved via application profiles and that not everything would require changes to RDA itself.

Mr. Attig also reviewed the set of "Follow-Up Actions for ALA" (http://alcts.ala.org/ccdablog/wp-content/uploads/2013/01/actions201301.pdf) he had compiled for CC:DA's consideration. Among his recommendations and related issues:

- The Rare Books and Manuscript Section (RBMS) Bibliographic Standards Committee will provide instructions for dealing with unnumbered sequences and other oddities of printing and numbering.

- Ms. Glennan and Mr. Attig will work together on some issues regarding dates associated with persons

- Mr. John Hostage (Harvard University) and Mr. Attig will confer on authorized access points for hearings in RDA Chapters 6 and 11.

- Mr. Attig will work with a small group on a proposal to delete abbreviations for place names from Appendix B.

- Mr. Rolla created a task force, and will compose its charge, to deal with the treatment of larger/smaller places. This will be informed by the work of the Task Force on Relationship Designators in RDA Appendix K and a larger effort in progress in the Subject Access Committee regarding places as Type 3 entities.

- The work of the Task Force on Sources of Information has been declared complete and the group was dismissed.

- Work will continue on machine-actionable data elements in Chapter 3, with additional input needed from the map, music, art, and rare materials communities.

- MLA and the Online Audiovisual Catalogers (OLAC) asked to take the lead regarding inconsistencies between the Statement of Responsibility element in Chapter 2 and the Performer, Narrator, Presenter, and Artistic and/or Technical Credit elements in Chapter 7. The consensus seemed to lean toward consolidating the elements rather than carrying on past practices. there could also be some impact on the Core status of the Statement of Responsibility.

- An informal group working under the auspices of the American Theological Library Association (ATLA) on preferred titles for parts of sacred scriptures has been inactive, but its work had raised many related questions. Mr. Attig and Mr. Myers will confer on this and report back to CC:DA on what needs to be done.

Mr. Dan Lipcan (Metropolitan Museum of Art) reported that the art library community has begun looking at RDA and its use for art catalogs and related literature. Although they are just beginning to discuss the issues, it is already clear that RDA continues the cataloging 
tradition of being text-biased. The community is looking into such notions as embedding the type of medium (prints, watercolors, etc.) into conventional titles and the relationship of the artist to the exhibition catalog (not as author, but as what?), with the intention of bringing issues to CC:DA sometime in the near future.

Respectfully submitted by

Jay Weitz

Senior Consulting Database Specialist, WorldCat Quality Management Division, OCLC

IFLA Cataloguing Section Liaison to ALA CC:DA

2013 February 14 


\section{APPENDIX IX: Report from ALA CC:DA, ALA Annual Conference 2013}

Report on the American Library Association's Committee on Cataloging: Description and Access, ALA Annual Conference, Chicago, Illinois, USA, 2013 June 29 and July 1

Submitted to the Standing Committee of the IFLA Cataloguing Section by the IFLA Cataloguing Section Liaison to ALA CC:DA

The American Library Association's Committee on Cataloging: Description and Access (CC:DA) met at the ALA Annual Conference in Chicago, Illinois, USA, on Saturday 2013 June 28, 1:00-5:30 P.M.; and Monday 2013 July 1, 8:30-11:30 A.M.

CC:DA Chair Mr. Peter Rolla (Harvard University) reported on motions and other actions taken by CC:DA between February and June 2013 (http://alcts.ala.org/ccdablog/wpcontent/uploads/2013/06/Chair-report-Annual-2013.pdf). With its mandate completed, the Task Force to Investigate Changes Affecting RDA in the Chicago Manual of Style, 16th edition, was disbanded with thanks.

Library of Congress (LC) Representative Mr. David Reser reported on activities and news from LC (http://alcts.ala.org/ccdablog/wp-content/uploads/2013/06/lc201306.pdf). Some of the highlights of his report:

- Ms. Geraldine Ostrove, cataloging policy specialist for music, retired on 2013 May 31.

- LC has made available for download two software code sets that convert current MARCXML records to BibFrame, with a demonstration area at http://bibframe.org/demos/ that includes sample collections from the BibFrame early experimenters.

- The first updates to the Library of Congress-Program for Cooperative Cataloging Policy Statements (LC-PCC PSs) for RDA were published in May 2013 and the second on July 9. The next update is scheduled for November 2013.

- LC fully implemented Resource Description and Access (RDA) on 2013 March 31 for all Authority work and most Bibliographic records.

- RDA changes to the LC/NACO Name Authority File, which were developed by the PCC Acceptable Headings Implementation Task Group were made during March 2013. These "Phase 2" changes updated Authority records that had defined predictable characteristics that were considered safe to do via machine manipulation. The same programmatic changes were performed on LC Bibliographic records during April, May, and June 2013. LC Subject Headings that were affected by the RDA Phase 2 changes were also updated, although there is currently no plan to revise the headings that include abbreviations not permitted in RDA (such as "ca." associated with dates in 6XX subfield \$y).

- As part of the 2013 July 9 update to the RDA Toolkit, headings for fictitious and legendary characters and animals with proper names may now be considered as 
creators or contributors to works. These names will now be established only in the Name Authority file using RDA instructions.

- Review of the LC Subject Headings Manual (SHM) in light of RDA is in progress and will be incorporated into Cataloger's Desktop in November 2013.

- Recent developments for the ALA-LC Romanization Tables include:

- Approved revisions to the Urdu, Pushto, and Sindhi tables.

- New Macedonian, Rusyn, Serbian, and Tamashek tables currently under review; the Macedonian and Serbian tables were developed from the current Serbian and Macedonian table.

- Revisions to the Bulgarian table currently out for constituent review.

- A Coptic proposal nearly complete.

All current ALA-LC Romanization Tables are now included in Cataloger's Desktop, where they can be searched and retrieved; they are also freely available on the Web at http://www.loc.gov/catdir/cpso/roman.html. A revision proposal for Tibetan based on the Wylie transliteration scheme is being developed, with no target date yet. Revision proposals for Mongolian and Uighur need additional editorial work and are awaiting automation support.

- Beginning on 2013 July 1, LC cataloging publications became available as free, downloadable PDFs through LC's Acquisitions and Bibliographic Access Directorate Website at http://www.loc.gov/aba/. This is part of a transition to online-only publication of LC Cataloging Distribution Service (CDS) cataloging documentation.

The outgoing ALA Representative to the JSC, Mr. John Attig (Pennsylvania State University), introduced his successor, Ms. Kathy Glennan (University of Maryland). The RDA release of May 2013 included the French and German RDA translations and the full rewording accomplished by Ms. Chris Oliver (McGill University). The July update includes all Joint Steering Committee (JSC) revisions from its November 2012 meeting. The November 2013 JSC agenda is expected to be lighter than recent ones, although it will include the proposal to rationalize all forms of place names, both as Authorized Access Points (AAPs) and as qualifiers.

A proposal on "Variant title as access point (RDA 6.27.4.1)"

(http://alcts.ala.org/ccdablog/wp-content/uploads/2013/05/jsc1305.pdf) had support in a straw poll. If accepted, it would have implications for other areas in RDA that follow a similar pattern. It was pointed out that the OCLC authority macro already accounts for this with the creation of appropriate fields 430 in Authority records.

The Task Force on Relationship Designators in RDA Appendix K reported on its continuing work on incorporating recommendations from the CC:DA meeting during January 2013 (http://alcts.ala.org/ccdablog/wp-content/uploads/2012/06/tf-appK5.pdf). It was clarified that the divisions of the appendix into sections was intended as an aid to human catalogers, not to impose meaning. The general Relationship Designators (RDs), which may be used to relate multiple entities (personal, corporate, and family), will be distributed where appropriate within the sections, with their definitions intact, with an eye toward helping catalogers. 
The Task Force on Instructions on Recording Relationships submitted its final report (http://alcts.ala.org/ccdablog/wp-content/uploads/2012/06/tf-relationships4.pdf). Ms. Glennan, Mr. Attig, and the task force will continue work on this, because it is not yet ready to become a proposal. Clarification is still needed on such questions as describing the relationships of accompanying material and contents.

The Task Force on Machine-Actionable Data Elements in RDA Chapter 3 submitted its interim report (http://alcts.ala.org/ccdablog/wp-content/uploads/2012/06/tf_MRdata4.pdf). Additional cases where machine action would be useful will be added to the report before it is sent to the JSC.

Although there remain questions about treaty dates and signatories both in MARC and in RDA, the revision proposal from the American Association of Law Libraries (AALL) regarding RDA instructions for treaties (http://alcts.ala.org/ccdablog/wpcontent/uploads/2013/05/aall2013-1.pdf) will be forwarded as written to the JSC.

The RDA Conference Forums and Programs Task Force reported that it was disbanding following this ALA Annual Conference after having presented six preconferences and 19 RDA forums since 2008.

MARBI Representative Mr. John Myers (Union College) reported that the MARC Advisory Committee (MAC) will continue the work of MARBI, which holds its final meeting at this Chicago conference. The exact relationship of the liaisons to MAC is still being defined. Two discussion papers and two proposals were on the agenda for MARBI:

- MARC Discussion Paper No. 2013-DP05, "Defining Indicator Values for Field 588 Source of Description Note in the MARC 21 Bibliographic Format" (http://www.loc.gov/marc/marbi/2013/2013-dp05.html) will return as a proposal based on Option 1, in which field 588 First Indicator "blank" will be defined as "No display constant generated." There was consideration of splitting Indicator " 0 " into the two different display constants proposed, but there was more support for divorcing the explicit textual aspect of the indicator from its use as a conceptual indication of the sort of data represented in the field.

- $\quad$ MARC Discussion Paper No. 2013-DP06, "Defining New Field 388 for Chronological Terms in the MARC 21 Authority Format" (http://www.loc.gov/marc/marbi/2013/2013-dp06.html) will return as a proposal. There was extensive discussion about distinguishing single works versus aggregate works, historical periods versus actual dates, and the date of creation versus the date of compilation or aggregation.

- MARC Proposal 2013-08, "Defining Subfield \$7 in the 8XX Series Added Entry Fields in the MARC 21 Bibliographic Record" (http://www.loc.gov/marc/marbi/2013/2013-08.html), adding indications of Type of Record and Bibliographic level in subfield \$7 in 8XX fields, was approved with minor changes.

- MARC Proposal 2013-09, "Defining Subfields for Qualifiers to Standard Identifiers in the MARC 21 Bibliographic, Authority, and Holdings Formats" (http://www.loc.gov/marc/marbi/2013/2013-09.html), adding subfield \$q (Qualifying Information )to fields 015 (National Bibliography Number), 020 (ISBN), 024 (Other 
Standard Identifier), and 027 (Standard Technical Report Number), was approved with minor edits.

ALA Publishing's Mr. Troy Linker reported that "fast track" changes to RDA are included in each and every release. In Cataloger's Desktop, RDA links to AACR2 go to the Cataloger's Desktop version of AACR2. The standard schedule of updates is now quarterly, but will be flexible. The major update will correspond to the JSC meeting. The AACR2 index is restored in the July 2013 update to Cataloger's Desktop. It also includes an upgraded workflow editor, the French and German RDA translations, and policy statements from the National Library of Australia (links to which may be toggled on and off). The English rewording of RDA was completed in May 2013, but some subsequent rewording or translations is still in progress. The Spanish translation is in its first draft and could be ready for November 2013, although February 2014 looks more likely. Other translations are in discussion or in progress; the Chinese translation will be in print only, not in the Toolkit. The Metadata Registry vocabulary will be integrated into the RDA Toolkit. A completely new cumulation of the print version of RDA will be made available in September 2013, representing all releases through July 2013. An e-book version of this print RDA will have internal links but will not link to any external sources, will have rudimentary searching capabilities that will depend upon the device on which it is read. There are currently around 2000 institutions subscribing to the RDA Toolkit, including subscribers from 67 countries. This is a shortfall from earlier projections, but it appears to be mostly a matter of users subscribing later than expected. There was some discussion about the possible development of a side-by-side display capability for direct comparison of different RDA translations. CC:DA webmaster Ms. Melanie Polutta reported that older archival materials, including CC:DA agendas going back to 2008 have been reconstructed and added to the new site (http://alcts.ala.org/ccdablog/?cat=11). The former CC:DA site (http://downloads.alcts.ala.org/ccda/) retains older agendas and documents. Ms. Polutta will continue to transfer documents from the old to the new site going back to 2005; this will include all task forces active in 2005 and onwards. Most pages on the new site include a "Print Friendly" icon.

Ms. Glennan reported on the activities of the Program for Cooperative Cataloging (PCC) (http://alcts.ala.org/ccdablog/wp-content/uploads/2013/06/PCC-Report-for-CCDA-June2013.pdf). Among her points:

- Recent updates to "PCC Post RDA Test Guidelines" (http://www.loc.gov/aba/pcc/rda/PCC\%20Post\%20RDA\%20Test\%20Guidelines.html \#Maintab), "Post Implementation Hybrid Record Guidelines" (http://www.loc.gov/aba/pcc/rda/PCC\%20RDA\%20guidelines/Post-RDAImplementation-Guidelines.html\#Hybrid), and "Frequently Asked Questions: Program for Cooperative Cataloging and RDA" (http://www.loc.gov/aba/pcc/rda/PCC-RDA-FAQ\%20Update\%2020130401.doc) are now available.

- Much work has been done on RDA Relationship Designators (RDs), including the completion of the "PCC Guidelines for the Application of Relationship Designators in Bibliographic Records" (http://www.loc.gov/aba/pcc/rda/PCC\%20RDA\%20guidelines/Relat-DesigGuidelines.docx). These guidelines will be refined with further experience. 
Suggestions for new RDs are funneled though the PCC Standing Committee on Standards, forwarded to CC:DA, and passed on to the JSC.

- The "LC $\square$ PCC PS for 9.19.1.4, Option (Fuller Form of Name)" (http://www.loc.gov/aba/rda/pdf/LC PCC PS 919 1 4 4 option\%20web.pdf) had been posted on the PCC Web site in February 2013. Because of the delay in updating the Toolkit in early 2013, it was declared in effect as of the posting, but has since been incorporated into RDA with the May 2013 update.

- The PCC Standing Committee on Standards continues to work through the LC-PCC PSs, now including new PSs and changes to existing ones. Plans are underway to move the CONSER Standard Record and BIBCO Standard Record Core element statements into the Toolkit.

- The PCC Standing Committee on Training has made RDA in NACO "bridge" training videos available on the Catalogers Learning Workshop (CLW) (http://www.loc.gov/catworkshop/RDA\%20training\%20materials/index.html) Web site. The Task Group on RDA NACO Training Materials is completing work on the new full NACO training materials for RDA.

The Task Force on Place Names reported that sections of RDA Chapter 16 remain in flux. Instructions are generally being simplified, standardizing treatment of place names regardless of the country, and allowing policy statements to decide national practices.

Ms. Kelley McGrath (University of Oregon) presented "Discussion Paper on the Inconsistency Between the Statement of Responsibility Element in Chapter 2 and the Performer, Narrator, Presenter and Artistic and/or Technical Credit Elements in Chapter 7" (http://alcts.ala.org/ccdablog/wp-content/uploads/2013/05/mla2013-1.pdf) for discussion. Mr. Attig noted that ISBD is silent regarding performers in statement of responsibility, although it does talk about major and minor responsibility. It will be difficult to devise a principle that will work in all cases, but perhaps Relationship Designators may be used to identify responsibilities in place of formal statements of responsibility. Ms. McGrath, Ms. Tracey Snyder (Cornell University), and Mr. Attig will continue work on this paper, in preparation for future presentation to the JSC.

Mr. Adam Schiff presented the paper "Pseudonymous Corporate Bodies" (http://alcts.ala.org/ccdablog/wp-content/uploads/2013/05/schiff2013-1.pdf), which resulted in a task force being formed to consider the issue of both corporate and family pseudonyms. Mr. Attig presented the paper "Colour Content (RDA 7.17)" (http://alcts.ala.org/ccdablog/wpcontent/uploads/2013/06/jsc1306.pdf). There was considerable discussion, including issues of black-and-white versus grayscale, tinting versus toning, and the histories of microfilming, lithography, and other graphic processes. There was also concern about how specific or general any recommendations should be. Mr. Attig will revise the paper in light of these discussions.

In his Chair's report, Mr. Rolla noted that the ALA Subject Access Committee (SAC) was proposing work on the subject chapters in RDA and inviting comments from CC:DA. The Art Libraries Society of North America (ARLIS/NA) is working on changes to RDA's treatment of art catalogs, including the role of illustrations in such resources, the relationship of the artist to the catalog, and the use of the artist's name as a catalog title. There was discussion of such RDs as "set to music as" and "dramatized as." Also discussed was the 
possibility of a reconciliation between RDA practices for unidentified publishers, distributors, manufacturers, etc. and the instructions about the data being "readily ascertainable." In the music cataloging community, this has come to be known as the "Cascading Vortex of Horror" $(\mathrm{CVOH})$ that threatens to result in absurd publication statements.

Respectfully submitted by

Jay Weitz

Senior Consulting Database Specialist, WorldCat Quality Management Division, OCLC

IFLA Cataloguing Section Liaison to ALA CC:DA

2013 July 18 


\section{APPENDIX X: Financial statement 2013}

\section{FINAL RESULT OF THE YEAR 2012}

\begin{tabular}{|c|c|c|c|c|}
\hline & Admin & $\begin{array}{r}\text { Consolidation of } \\
\text { conceptual model } \\
\text { (D3.5.13-2.11) }\end{array}$ & $\begin{array}{r}\text { Development of IFLA } \\
\text { namespaces for } \\
\text { bibliographic } \\
\text { standards (E3.13.4- } \\
1 / 12 \text { ) }\end{array}$ & Total \\
\hline Allotment, 1 Jan. 2012 & 400 & 6000 & 2000 & 8400 \\
\hline $\begin{array}{l}\text { Expenditures to 31. Dec. } \\
2012\end{array}$ & 0 & $5117^{a}$ & $1862^{b}$ & 6979 \\
\hline Balance, 31 Dec. 2012 & $\begin{array}{r}400-> \\
0\end{array}$ & $883->0$ & $138->0$ & $\mathbf{0}$ \\
\hline
\end{tabular}

Notes:

- All amounts in Euros (EUR).

- IFLA allots new funds at beginning of each year. Balances returned to IFLA at end of year.

a) Namespaces dereferencing EUR 200. FRBR RG meeting in London in April 2012, EUR 3 018,17 (EUR 101 Dunsire, EUR 921,22 Riva, EUR 578,25 Willer, EUR 213,94 + EUR 1 203,76 Zumer). CRM meeting Heraklion EUR 355,91 (Riva). Other costs for April-May meetings EUR 825,98 (Riva). FRBR/CRM harmonisation WG, Amersfoort (The Netherlands), November 19-22 (EUR 658,82 Zumer) -> EUR 5058,82. The project reimbursement total for the year 2012 was EUR 5117 (IFLA HQ).

b) Attendance at Libraries in the Digital Age (LIDA) conference and ISBD/XML Study Group meeting, Zadar, Croatia, 18-21 June 2012, GBP 519,51 (Dunsire), Attendance at WLIC, Helsinki, Finland, 11-17 Aug 2012, GBP 691,89 (Dunsire). Attendance at 16. Seminar Arhivi, Knjižnice, Muzeji, Poreć, Croatia, 28-30 Nov 2012, GBP 246,33(Dunsire). The GBP amounts 1 457,73 -> EUR 1 857. The project reimbursement total for the year 2012 was EUR 1862 (IFLA HQ).

During the year 2012 the ISBD RG was additionally approved EUR 1191 (not included above) for a Madrid meeting in in order to finalise the document "ISBD Profile in RDA" as a continuation of the Project no. D3.4.13-1/11 (official funding for 2012 was not approved). 


\section{PROJECTED CASH FLOW 2013}

\begin{tabular}{|c|c|c|c|c|}
\hline & Admin & $\begin{array}{r}\text { FRBR: } \\
\text { Reassessment } \\
\text { of properties in } \\
\text { a consolidated } \\
\text { conceptual } \\
\text { model (G3.13.1- } \\
1 / 13)\end{array}$ & $\begin{array}{l}\text { ISBD Namespaces } \\
\text { Alignments and } \\
\text { Publication as } \\
\text { Linked Data } \\
\text { (G3.13.2-1/13) }\end{array}$ & Total \\
\hline Allotment, 1 Jan. 2013 & 300 & 3000 & 1500 & 4800 \\
\hline $\begin{array}{l}\text { Expenditures to 31. July } \\
2013\end{array}$ & 0 & 0 & $0^{\mathrm{a}}$ & \\
\hline $\begin{array}{l}\text { Projected exp. July-Dec. } \\
2013\end{array}$ & 300 & 3000 & 1500 & 4800 \\
\hline Balance, 31 Dec. 2013 & 0 & 0 & 0 & $\mathbf{0}$ \\
\hline
\end{tabular}

\section{Notes:}

- $\quad$ All amounts in Euros (EUR)

- IFLA allots new funds at beginning of each year. Balances returned to IFLA at end of year.

a) ISBD Namespaces Alignments, etc. project activities: individual preparatory work and shared work via e-mail, skype and wiki done in the first half of 2013; face-to-face working meeting is planned for the second half of 2013 regarding further developments in relevant groups (FRBR RG, JSC, DCMI etc., and specifically Namespaces Task Group)

- $\quad$ The project IFLA Namespace Development, Co-ordination, and Training (Gordon Dunsire, G3.29.11/13) was submitted through the Classification and Indexing Section, and received funding with Euro 7000 . 


\section{BUDGET PROPOSAL 2014}

\begin{tabular}{|l|r|r|r|r|r|r|}
\hline & Admin & $\begin{array}{r}\text { Consolidation } \\
\text { of conceptual }_{\text {models }}\end{array}$ & ISBD RG $^{\mathbf{b}}$ & $\begin{array}{r}\text { IFLA } \\
\text { Namespaces } \\
\text { task group }^{\mathbf{c}}\end{array}$ & $\begin{array}{r}\text { Revision } \\
\text { ICP }^{\mathbf{d}}\end{array}$ & Total \\
\hline Expenditures 2014 & 300 & 3000 & 2000 & & $0 ?$ & \\
\hline $\begin{array}{l}\text { Balance, 31 Dec. } \\
\mathbf{2 0 1 4}\end{array}$ & & & & & & \\
\hline
\end{tabular}

\section{Notes:}

- All amounts in Euros (EUR).

- IFLA allots new funds at beginning of each year. Balances returned to IFLA at end of year.

a) 2012 the FRBR RG applied for funding of a 2-year project, that continues the consolidation work. 2013 the project was allotted EUR 3000.

b) 2013 the ISBD RG was approved EUR 1500 for one year project on development of ISBD namespaces alignments. In 2014 the continuation of these activities is planned together with those on the preparation for the ISBD regular review process the start of which to be formalized in August 2014. The estimated sum for the year 2014 is EUR 2000.

c) 2013 this group applied for funding through the Classification and Indexing section.

d) The work is planned to be conducted by email, Skype, plus any in-person meetings during the IFLA conference. 


\title{
APPENDIX XI: Draft strategic plan
}

\section{Strategic Plan, 2013-2015}

\section{Mission}

The Cataloguing Section of IFLA strives to be the leader in international developments in cataloguing theory, activities, and standards development. The Section analyses the principles and functions of cataloguing activities for all types of materials and media, including both bibliographic and authority information, for the benefit of all kinds of users. The Section proposes and develops eataloguing rules, guidelines, and standards for bibliographic information, taking into account the developing electronic and networked environment in order to promote universal access to and exchange of bibliographic and authority information.

The Section also provides leadership in the development of various standards and guidelines related to data modelling (e.g. FRBR, FRAD, FRSAD, ISBD), bibliographic activities and tools. such as corporate name headings, authority entries, OPAC displays and metadata standards. The section cooperates with other sections as needed and desired.

\section{Action plan for 2013}

- FRBR: Explore the preparation of a consolidated document for IFLA's FRBR family of conceptual models in an entity-relationship formulation

- Promote IFLA standards: Participate in the development of namespaces for all IFLA bibliographic standards, including the ISBD, FRBR, FRAD, and FRSAD and in connection with this promote and position the IFLA standards and models in the semantic web

- Prepare the update of the Statement of International Cataloguing Principles (ICP).

\section{Goals}

1. Promote the development and maintenance of the Statement of International Cataloguing Principles (ICP) for bibliographic description and access

\author{
Mission: The main purpose of the ICP is to state the common set of international \\ cataloguing principles
}

1.1. Following the successful international agreement on the Statement of International Cataloguing Principles (ICP) ICP and its Glossary in February 2009 , encourage the cataloguing rule makers of the world to follow these principles.

1.2. Encourage further translations of the ICP Statement of International Cataloguing Principles-and Glossary; make those translations and other information available on the IFLA web site.

1.3. Modify the ICP Statement of International Cataloguing Principles (ICP) as necessary for today's rapidly evolving environment based on regular evaluation of the principles. The first review is 
scheduled for 2014. -or sooner as deemed necessary. The first evaluation will take place in $2011 / 2012$ preparing a recommendation for the SC on whether a review is needed or not by the 2012 meetings.

1.4. Be prepared to form a working group, in collaboration with other relevant sections, to lool further into the need of separating the specific cataloguing rules from the principles and explore the need to expand the statement further towards becoming an international cataloguing code. [the pros and cons and the realism on working towards an international eataloguing code in IFLA will be discused at the SC meetings in 2012$]$

\section{Continue development and use of IFLA's FRBR family of conceptual models.}

Mission: The main purpose of the FRBR family is to be a conceptual model and provide a reference model for the bibliographic universe.

2.1. Maintain and develop the FRBR model in an entity-relationship formulation.

2.1.1. Assess any amendments to be recommended by the Working Group on Aggregates; (The report is finished and presented to the FRBR RG)

2.1.2. Review the attributes of the Group 1 entities;

2.1.3. Assess other reviewing suggestions and follow through as appropriate.

2.2. Explore the preparation of Prepare a consolidated document for IFLA's FRBR family of conceptual models in an entity-relationship formulation.

2.2.1. Determine the scope and format of a consolidated conceptual model document;

2.2.2. Identify areas in which the FRAD and FRSAD models result in revisions of the FRBR model

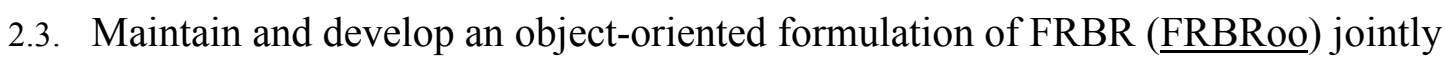
with CIDOC-CRM.

2.3.1. Develop a "core" FRBRoo model for implementation;

2.3.2. Support the development of an implementation prototype;

2.3.3. Expand FRBRoo to include additional entities, attributes and relationships from the FRAD and FRSAD models;

2.3.4. Encourage the further harmonisation of conceptual models by participating in joint work with the archival community and other relevant communities.

2.4. Develop, update and make available guidelines and interpretative documents to assist those applying IFLA's FRBR family of conceptual models.

2.4.1. Prepare new FAQs for the FRBR pages on the IFLA website, starting with those on the expression entity;

2.4.2. Provide interpretative text on the treatment of aggregates within FRBR.

2.5. Maintain liaisons between the FRBR Review Group and the ISBD Review Group and with rule-makers in order to have the main principles of FRBR and FRAD reflected in cataloguing codes.

2.6. Maintain liaisons with other IFLA units, vendor groups and with other relevant groups to assure widespread awareness and use of FRBR, FRAD and FRSAD. 
2.7. Monitor and publicise translations of documents within the FRBR family of models.

\section{Continue ISBD revision}

Mission: The main purpose of the ISBD is to serve as a principal standard to promote universal bibliographic control by offering consistency when sharing bibliographic information.

\section{The Strategy for the ISBD is under evaluation and a revised strategy is expected in 2014}

3.1. Maintain and develop the ISBD content standard; Assess any amendments to be recommended by the Review Group.

3.2. Develop mapping between ISBD and the FRBR family of conceptual models in the RDF environment to inform the further development of ISBD itself, and increase the understanding of the relations between ISBD and FRBR.

3.3. Provide leadership in encouraging harmonization of existing cataloguing rules with the ISBD through communication with rule-making bodies internationally by forming liaison relationships between each rule-making body and the ISBD Review Group.

3.4. Develop and maintain representations of the ISBD that are compatible with current electronic and semantic web environments for resource discovery and the management of metadata for use in digital and non-digital catalogues.

3.5. Maintain liaisons with the Permanent UNIMARC Committee, the ISSN Network, and the International Association of Music Libraries, Archives and

Documentation Centres (IAML), with other IFLA units, and with other relevant groups to assure widespread use of the ISBD as a metadata content standard.

3.6. Encourage translations of the consolidated ISBD

3.7. Develop training material centred on definitions, structure and the use of ISBD for rule making bodies and in general for teachers, cataloguers, etc.

\section{Develop additional approaches, standards, rules, and lists for information that} provide access to bibliographic and authority data in all languages.

4.1. Participate in the development of namespaces for all IFLA bibliographic standards

4.2. MulDiCat: Establish an infrastructure for MulDiCat in order to Hupdate MulDiCat on the IFLA Web site in the Open metadata registry (OMR) and encourage the addition of other language contributions to assist in translation and provide consistent vocabulary for IFLA publications/standards in the area of bibliographic control. Pursue the possibilities of establishing the terms as a Web registry or other means to facilitate free access to these terms on the Web.

4.3. Support the work on the Virtual International Authority File (VIAF) project and share information about the project.

4.4. Names of Persons and Anonymous Classics: Pursue the possibilities of establishing an infrastructure for Names of Persons and Anonymous Classics which is easy to maintain and freely available on the Web Continue updating the content of Names of Persons. When this is in place invite comments, additions, 
and updates and develop contacts for work on Anonymous Classics for Latin America. Consider the best possible way of publishing the work.

4.5. Publish Anonymous Classics, Part 3, Africa. Develop contacts for work on Part 2, Latin America.

4.6. Collaborate with other international initiatives and solutions outside IFLA if appropriate in order to achieve the Sections goals

5. Explore opportunities for promoting cataloguing activities, especially for developing countries.

5.1. Ensure that the section's standards, guidelines and reports are available in print and/or on the IFLA website.

5.2. Continue to promote bibliographic standards and information about cataloguing developments around the world via documents from Standing Committee groups, and the Section newsletter and information in International Cataloguing and Bibliographic Control.

5.3. Provide updated information for IFLA's listing of standards.

6. Provide information about the work of the Section and Standing Committee.

6.1. Assure distribution of all relevant documents to all Section members.

6.2. Continue communication of Section and Standing Committee activities through the Section newsletter, the open programme of the Section, the IFLA website, ICBC, CATSMAIL (the Section list), etc.

6.3. Post the strategic plan of the Section on the IFLA website.

6.4. Encourage translations of Section documents and of open programme papers.

\section{Promote membership in the Section, emphasising a broader geographic} representation on the Standing Committee.

7.1. Involve more representatives from existing institutional members in attending meetings of the Standing Committee and in participating in the various Working Groups of the Section by emphasising opportunities in the Section newsletter and via CATSMAIL (the Section list).

7.2. Send information on the activities of the Section to library associations in underrepresented regions of the world, to IFLA offices for Asia, Africa, and Latin America, and to chairs of sections in IFLA Division III. 


\section{APPENDIX XII: Singapore meetings: FRBR RG}

The FRBR RG met twice. Sunday August 18 (12:00-13:30) for a business meeting and Monday August 19 (9:30-14:00) as a working meeting to focus on model consolidation.

1) The FRBR Review Group recommended that Chris Oliver (Canada), newly elected RG member, be appointed as the new FRBR RG chair for 2013-2015.

(approved by the SC)

2) Update on the www.frbr.org domain. The FRBR blog formerly maintained by William Denton is no longer active and the domain name has been offered to the FRBR RG. There is a desire to keep the registration alive to keep the information presently on the site available. There is a small charge for annual registration.

Proposal that the Cataloguing Section pay this with administrative funds. (approved by the SC)

3) The RG recommended the addition of Marie Balikova (National Library of the Czech Republic) as corresponding member. (approved by the SC)

4) During the August 19 meeting the RG heard a presentation by Patrick Le Bœuf on PRESSoo, an object-oriented extension of FRBRoo to model serial publications. This work has been the initiative of the BnF and the ISSN International Centre to meet the Centre's needs. It is in the context of a long-standing desire to have a fuller account of serials in FRBR. This version of PRESSoo will be presented in October at the joint FRBR/CIDOC CRM meeting to receive comments from the CRM point of view.

5) During the model consolidation part of the agenda the RG was able to review the previous notes from 2012 on entities and primary relationships and refine some aspects. Even though no new sections were begun, the newly elected RG members present were able to get up to speed on and endorse the decisions taken so far.

6) The RG recommended the creation of a Model Consolidation Editorial Group with four members: Patrick Le Bœuf, Pat Riva, Miriam Säfström, Maja Žumer.

(approved by the SC)

7) The RG plans a consolidation working meeting on October 14-15, 2013, to be hosted by the BnF in Paris. The ISBD RG plans to meeting October 16-18, permitting joint attendance of several liaison members. The FRBR/CIDOC CRM Harmonisation Group will hold its meeting October 21-25, 2013 in Heraklion, Crete, Greece. FRBRoo version 2.0 should be finalized at that meeting.

8) The RG raised one issue relating to translation of standards to forward to the WG on a Standards Manual via the Cataloguing Section representative. For standards which maintain namespaces, any translation agreement for the text or report relating to the standard should also include responsibility for the translation of any existing namespaces. This is important for ensuring the consistent use of terminology in all versions of the standard. 


\title{
APPENDIX XIII: Singapore meetings: ISBD RG
}

\author{
the ISBD RG Meeting, Helsinki, 2012
}

IFLA, ISBD Review Group, Singapore, 2013. Draft Minutes

The minutes ${ }^{8}$ were adopted without changes.

4. Elections

4.1. Review Group members

The ISBD Review Group issued a call for nominations for members to serve a four year term (2013-2017), which can be once renewed. Three positions were available to replace members whose second term ends in 2013. Four members completed their first terms in 2013, and they expressed interest in being renewed. The nominations received were María Violeta Bertolini (Instituto de Formación Técnica Superior No. 13, Buenos Aires, Argentina), Lynne Howarth (University of Toronto, Canada) and Ricardo Santos Muñoz (Biblioteca Nacional de España). These nominations were reported at the Cataloguing Section's Standing Committee meeting, 17 August 2013, and were approved.

4.2. Corresponding members and liaisons

M. Willer proposed the nomination of Dorothy McGarry as the corresponding and honorary member for her contributions to the RG, and her great experience in the ISBD standardization processes. The proposal was unanimously accepted. This nomination was also approved by the Cataloguing Section's Standing Committee.

It was discussed that Karin Kleiber, member of the Bibliography Section be formally nominated as a liaison from that section to the ISBD RG; she has been on the mailing list of the RG since 2012 because of the Section's expressed interest in ISBD/RDA alignments, specifically ISBD in RDA Profile.

Action 1/13: M. Willer and A. Cato, Bibliography Section's Standing Committee chair (2013-) to formalize the liaison between ISBD RG and Bibliography Section's SC.

4.3. Thanks to outgoing members

M. Willer thanked the outgoing members Renate Gömpel, Glenn Patton and Dorothy McGarry for their contribution to the development of the ISBD, especially for their support of the work on the ISBD consolidated edition.

5. Cataloguing Section's ISBD - Strategic Plan for ISBD review

Prior to the ISBD RG's meeting in Singapore the Cataloguing Section's chair H. H. Hansen and officer M. Saström issued a discussion paper regarding the future of the development and maintenance of the ISBD as an IFLA standard, and whether it is needed to be developed any further when some consider RDA: resource description and access to be a "de-facto-standard in large parts of the world".

The ISBD RG commented extensively on the discussion paper, and a formal response was sent to H. H. Hansen. The discussion at the RG's meeting confirmed the following views: "The status of the ISBD as the IFLA bibliographic standard is crucial to the functioning of the Universal Bibliographic Control, and its relation to the RDA, as one of the cataloguing rules. [...] The Cataloguing Section should be the place for truly international reflections on today's cataloguing, basing on FRBR and the Web of data, and taking its specific agenda into account:

- thinking about international exchanges among national bibliographies (UBC): providing normative tools for national bibliographies and expressing these normative tools as

8 http://www.ifla.org/files/assets/cataloguing/isbdrg/meeting_2012.pdf 
cataloguing rules in both large and small libraries (RDA is one such cataloguing code, it IFLA, ISBD Review Group, Singapore, 2013. Draft Minutes

was designed so as to meet first the needs of local cataloguing, and only then the needs of bibliographic interchange);

- taking into account all countries (with their various levels of development, various cultures, etc.) This implies an in-depth revision of the ISBD (as demonstrated by the work done on alignments) so that it can be adapted to the current environment, rather than abandoned and substituted with a code that was developed outside IFLA, with no genuine international representation. [...] It is important to keep the ISBD as the reference normative document when it comes to bibliographic description, at a higher level than any particular code." 9 6. Matters arising from the Minutes of the Helsinki meeting and Action List 6.1 Action List

Action List, 3/2011, San Juan meeting:

ISBD consolidated edition online: M. Willer reported on her correspondence with F. Bradly, Manager, Member Services and Development in March/April 2013 about the posting of the online version on the ISBD web pages. In April F. Bradly informed M. Willer of the following status of her negotiations:

"The Professional Committee met earlier this month, and considered this topic. The difficulty is that the policy is written for journals which consist of a compilation of articles, or multiauthored chapters of a monograph. The redbacks are attributed to a single author - the committee of contributors. We also argue that IFLA should be a designated institutional repository as the authorship falls under the auspices of work produced (and sometimes funded by) IFLA. I will check further into the possibilities of designating the volumes as an "article"." The meeting emphasized once again the importance to have the online version of the ISBD consolidated edition published in order to meet IFLA's mission about its open standards for further development and use of ISBD namespaces in publishing bibliographic linked open data, the mapping and alignment activities with IFLA models and other communities' standards, its use in the planned development of the Guidelines for use of the ISBD, and Specialized translation guidelines for ISBD namespaces, and the requirements expressed by other bodies/communities to consult and use the standard in their activities, such as RDA and DCMI. To meet these requirements it was decided to publish the pre-print version online on the RG's site.

Action 2/13: M. Willer and A. Galeffi prepare and publish the ISBD, March 2011 version online asap

Action List, 2011, Glasgow meeting:

Information only: actions partly postponed, partly outstanding depending on the RDA/ISSN discussions; to be reviewed again during the ISBD revision process, except for:

Action 14/11: New description, change of title (CJK): ISSN to send resolution paper in November 2013; continues as actions 17/12 \& 8/13.

Action 16/11: Mode of issuance and Frequency: ISSN to send resolution paper in November 2013: outstanding

Action List, 2012, Helsinki meeting:

Action 1/12: Send the ISBD Strategic Plan for further comments and final approval to the ISBD RG members. Done ${ }^{10}$

\footnotetext{
9 See Appendix 1.

10

http://www.ifla.org/files/assets/cataloguing/isbd/OtherDocumentation/ISBD2R OF20Mapping20v1_1.pdf. See also discussion paper accompanying the document,
} 
IFLA, ISBD Review Group, Singapore, 2013. Draft Minutes

As the Cataloguing Section's Strategic plan was for the period 2011-2013, and is laid out at a general level, the ISBD RG itemized this plan from the point of view of various activities that inform future development of the ISBD. This requires a broader perspective of bibliographic standards in the Semantic Web, including the FR-family of conceptual models and the UNIMARC bibliographic format.

Therefore, the ISBD RG defined the strategic plan for 2011-2015 for the process that is necessary to prepare for the revision of the ISBD in four year time, following the general rule for standards revision.

The Cataloguing Section's revised Strategic Plan, 2013-2015 was discussed at the Standing Committee's meeting, 22 Aug.; it was decided that "3. Continue ISBD revision: The Strategy for the ISBD is under evaluation [by the Standing Committee] and a revised strategy is expected in 2014." (see Appendix 2)

Action 3/13: M. Willer and A. Galeffi to publish CS's \& ISBD RG Strategic plan for 20132015 on the RG's website.

Action 2/12: ISBD RG to propose its representative to the Cataloguing Section's ICP Review Task Group. Done

Action 3/12: Send the Mapping ISBD area 0 to ROF document to the CS's Standing Committee for final approval; publish the document on the ISBD RG's website; continues as action 18/12. Done ${ }^{11}$

Action 4/12: Follow up developments regarding publication of the RDA/ONIX Framework namespace, and start the implementation of the ISBD/ROF namespaces mapping as appropriate. ISBD/XML SG: ongoing

Action 5/12: Consider developing specialized translation guidelines for ISBD namespaces: ongoing

Action 6/12: Plan work on Guidelines for use of ISBD as Linked Data for 2013-2014:

Postponed for 2014

Action 7/12: Write Resource vs WEMI entity resolution: discussion paper. ISBD/XML SG:

Done

Action 8/12: Develop the ISBD AP as conditions are met. ISBD/XML SG: discussion ongoing

Action 9/12: Report on any issues relevant to the ISBD revision process. ISBD/XML SG: ongoing

Action 10/12: Develop a diagram of mappings/alignments and related projects. Done The document Alignments between the namespaces of ISBD, other IFLA standards, and external standards was prepared by the ISBD/XML SG as requested by the ISBD RG; it was not discussed at the meeting. Executive decision needed for the action.

Action 4/13: ISBD/XML SG to review the Alignments between the namespaces of ISBD, other IFLA standards, and external standards at its Paris meeting, October 2013; M. Willer send to ISBD RG for comment and adoption; publish on ISBD/XML SG's website.

Action 11/12: Volunteers are invited to join the ISBD/XML Study Group. Done; new members M. V. Bertini and M. Gentili-Tedeschi.

Actions 4/12 to 11/12 and 13/12 come under the terms of activity of the ISBD/XML Study Group. The first version of the documents was reviewed, while in-depth discussion will follow during the Paris meeting, 16-18 October 2013 as part of the Project ISBD Namespaces

http: //www.ifla.org/files/assets/cataloguing/isbd/OtherDocumentation/ISBD\%2 0 to20JSC20discussion\%20paper $\div 202$.pdf

11 http://www.ifla.org/node/1795 
Alignments and Publication as Linked Data (G3.13.2-1/13). For details, see the ISBD/XML SG's minutes. ${ }^{12}$

IFLA, ISBD Review Group, Singapore, 2013. Draft Minutes

Action 12/12: J. Hostage will answer the question on the use of ISBD. Done

Action 13/12: Monitor developments around the need to publish ISBD unconstrained namespaces, and act as needed. ISBD/XML SG: ISBD unconstrained elements and other extensions by G. Dunsire, 2013/07/29. Done

Action 14/12: G. Dunsire will answer the email, and help in wording the request to the Library of Congress to register ISBD Area 0 as a Genre/Form Code and Term Source Codes, and ISBD as a Descriptive Convention Source Code; check with PUC for a need of similar request for UNIMARC. Done

Action 15/12: Finish the ISBD/RDA profile document; report on any issues relevant to the ISBD revision process. Done

The working group meeting took place in Madrid, 19 and 20 September 2012, for which extra funding was approved (EUR 1.191). The members are: E. Escolano Rodríguez, M. Gentili-Tedeschi, F. Lereshe and D. McGarry, The version Draft, 27 May 2013 was sent to ISBD RG members for voting on 4 June 2013. No comments were received.

Also: RDA Appendix D.1 ISBD consolidated edition (punctuation), approved by the ISBD RG; revised version with response sent to JSC/RDA 2013/07/05. Done; it was decided not to publish this document on the RG's website, only in the wiki.

Action 5/13: M. Willer to send the ISBD Profile in RDA to the Cataloguing and Bibliography Sections' standing committees for comments and adoption by 30 November 2013; after adoption, post on the RG's website.

Action 6/13: M. Willer to send ISBD Profile in RDA with discussion paper to JSC/RDA for comments.

Action 16/12: Send the Alignment of the ISBD/RDA document to the CS's Standing Committee for final approval, and then publish it on the ISBD RG's website. Done5 During the discussion process with JSC/RDA, it was noted that correction should be made in alignment of 7.0.3, and a new version published.

Action 7/13: G. Dunsire to revise the Alignment of the ISBD/RDA, and M. Willer to send it for posting on the RG's website.

Action 17/12: Comment on ISSN Network's title changes in CJK languages proposal. Not done ISSN IC will send their decision to the ISBD RG and JSC/RDA after their October 2013 meeting.

Action 8/13: ISBD RG to review the ISSN document on title changes in CJK languages. Action 18/12: Re-send the ISBD RG's proposals on the ISBD/RDA alignment and ISBD Area 0/ROF mapping to the JSC/RDA on the proposal forms. Done; ISBD Area 0/ROF namespaces mapping: outstanding.

JSC with ISBD RG discussions/responses to both mapping/alignment documents, and also the RDA Appendix D.1 were discussed and approved by the ISBD RG prior to the Singapore meeting as: ISBD RG response to JSC/RDA Response: 6JSC/ISBD/Discussion/1 Alignment of ISBD and RDA Element Sets, and

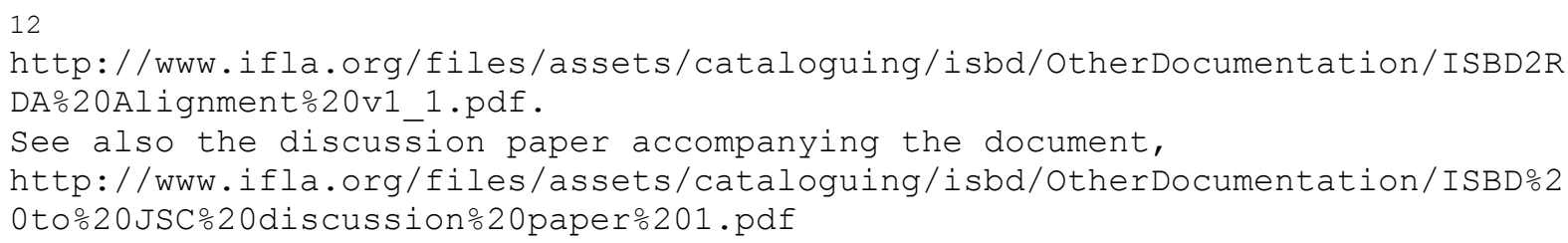


6JSC/ISBD/Discussion/2 and Mapping of ISBD Area 0. It was decided to publish the document.

Action 9/13: M. Willer to send documents 6JSC/ISBD/Discussion/1/JSC/ response/ISBD response,JSC/ISBD/Discussion/2/JSC/ response/ISBD response, July 4, 2013 for posting on the RG's website. Also: M. Willer to collate the responses to this paper and send it for posting on the RG's website.

Action 19/12: Review Glasgow Outcomes, and propose actions based on the priorities of the ISBD Strategic Plan. Done

ISBD RG discussed the work done so far, and concluded that it has fulfilled all the tasks regarding ISBD/RDA alignment. ISBD RG decided that it can update the mapping documents with ISBD revisions, but will not update with RDA revisions, especially as RDA is constantly changing while RG has no capacity to follow it. However, ISBD RG is open to further dialogue on the improvement of interoperability between ISBD and RDA based on the JSC constituency responses and proposed activities. The major impact on the alignment could be the RDA/ISBD alignment, which is considered complementary to ISBD/RDA one, and which can resolve some detailed issues recognized during the Glasgow meeting.

Action 20/12: Task group to prepare the proposal for the survey on use of ISBD. Done. A draft survey on use of ISBD prepared by A. Galeffi, J. Hostage, I. Kavčič and D. McGarry was discussed and comments accepted. The new version should be sent to the RG and Cataloguing Sections's SC for approval. It is planned that the survey and its preliminary analysis of the results will be finished by February/March 2014. The results of the survey will be sent to the RG and Cataloguing Sections's SC for further discussions on ISBD - Strategic Plan.

Action 10/13: A. Galeffi, J. Hostage, I. Kavčič, D. McGarry to distribute the revised version of the survey for approval; distribute the survey; preliminary results to be sent to the ISBD RG and Cataloguing Section's SC by March/April 2014.

6.2 Other mapping activities

6.2.1 ISBD and REICAT mapping

The ISBD and REICAT mapping was sent to the ISBD RG by S. Forassiepi as part of his research for a master's thesis under the supervision of Prof. Mauro Guerrini. It was decided to review and as necessary to update the document and publish it on the RG's website as part of the RG's activity to "encourage harmonization of existing cataloguing rules with the ISBD" (3.3). It should be clearly acknowledged that this is a research document, and not the official mapping issued by the publishers of REICAT.

Action 11/13: A. Galeffi, M. Gentili-Tedeschi and F. Leresche will review the ISBD/REICAT mapping and contact $\mathrm{S}$. Forassiepi as required; publish the research mapping on RG's website.

6.2.2 ISBD/XML Study Group: status, membership and activities (report by F. Leresche)

ISBD RG acknowledged the SG's activities and adopted the report (see above). F. Leresche proposed to change the name of the SG to more appropriately represent its changed tasks. The meeting, as well as the Cataloguing Section's SC approved of the change of the name to: ISBD Linked Data Study Group.

Action 12/13: F. Leresche and A. Galeffi to update the ISBD/XML SG's website with the information on the change of the SG's name.

7. Chair's report

7.1. Project ISBD Namespaces Alignments and Publication as Linked Data (G3.13.2-

1/13) 
An amount of 1500 Euros was allocated in 2013 for funding the project on ISBD Namespaces Alignments and Publication as Linked Data. The project is part of the ISBD Linked Data SG's remit. The SG's project meeting will take place in Paris, 1619 October, 2013.

7.2. Publications and presentations

7.2.1. The French translation of the ISBD consolidated edition (2011) is available on the BnF website: http://www.bnf.fr/documents/isbd_trad_francais.pdf; ISBD Area 0 vocabulary namespaces were published in OMR ${ }^{13}$; the Spanish translation of the ISBD consolidated edition (2011) is available at http://www.ifla.org/files/assets/hq/publications/series/44-es.pdf.

7.2.2. List of presentations and publications: see Appendix 3

Information: Cataloguing \& Classification Quarterly issued a call for papers for a special issue which will be devoted to the evaluation and adoption of ISBD:

International Standard Bibliographic Description, consolidated edition, published in 2011; guest editors are M. Willer, L. Howarth and J. Hostage. Planned publication date is 2014

8. Status of projects and issues arising during IFLA meetings: updates

8.1. Cataloguing Section's Standing Committee:

8.1.1. Strategic plan - discussed and reported above

8.1.2. Open Session meeting: Cataloguing Section will join its time with Bibliography Session on the topic UBC: Use and Re-use of Bibliographic Data

8.2. FRBR Review Group: RG will hold its consolidation meeting in Paris, 13-14 October, 2013, and members of the ISBD/XML SG will join as the discussion will be focused on FRBR attributes.

8.3. Namespaces Technical Group (report by G. Dunsire chair): Guidelines for translations of IFLA namespaces in RDF, draft, version 2.0 was approved, thus specific guidelines for ISBD namespaces can start to be drafted; Guidelines on using and extending IFLA namespaces, draft version to be developed further, as well as Issues of constrained and unconstrained namespaces, draft; both are relevant to further development and use of ISBD namespaces as part of the ISBD Linked Data SG's activities.

8.4. Permanent UNIMARC Committee (report by I. Lopes Cordeiro, UNIMARC Core Activity director): PUC funded the project UNIMARC in RDF for 2013; part of the project is to align UNIMARC/ISBD namespaces, and to report on the outstanding issues for both standards. The project members presented the paper on these issues at the conference. ${ }^{14}$

8.5. Identification of issues for project proposal for 2014

The item was not discussed due to the lack of time. The members of the ISBD Linked Data SG will consider this issue during their meeting in Paris as the continuation of this year's project, and will make a proposal.

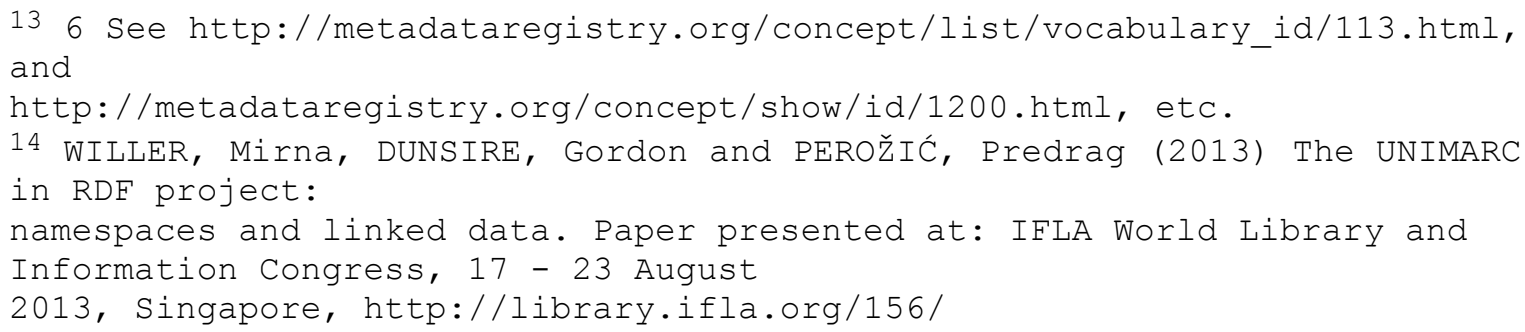


Action 13/13: The project meeting in Paris, Oct. 2013 to identify issues for project proposal for 2014; M. Willer to distribute the proposal to members for adoption and submit.

9. Any other business

There was no other business.

Respectfully submitted by

Mirna Willer, ISBD Review Group chair, Zagreb, 21 October 2013

\section{Appendix 1}

ISBR Review Group response to the call for view on the Cataloguing Section's paper on ISBD Strategy, 2013

e-mail to Hanne H. Hansen, 7 August, 2013

Dear Hanne and colleagues,

ISBD Review Group had extensive and very fruitful discussions on the questions you put regarding ISBD strategy and further development.

The majority of the members agree with the status of the ISBD as the IFLA bibliographic standard crucial to the functioning of the Universal Bibliographic Control, and its relation to the RDA, as one of the cataloguing rules. This view was presented in the document by Françoise Leresche, and adopted by that majority.

There were two other opinions, however, that do not share such a view, and that point to the fact that the today's world has changed so much, and that economic and other factors will influence the adoption of one cataloguing code - RDA, as they do not see viable that national cataloguing bodies would consider developing particular national cataloguing rules. ISBD as an IFLA standard is seen either only as a display format, or, vaguely, as some kind of necessity related to FRBR.

There is still another opinion, expressed by the previous chair of the ISBD RG, Elena Escolano Rodriguez. Elena endorses F. Leresche's view, but she reminds of the discussions on IFLA's role in bibliographic Standards document on reinstating the UBC going on in 2010 in all Division IV sections.

Elena additionally reminds us all of the activities related to ISBD and UBC based on the IFLA Strategic plan, 2010-2015, where the third mission still reads:

“ - drives high standards in library and information services and professional practice;" And as Goals reads: "To advance the profession through the development of standards and the promotion of specialised knowledge within the professional practice..."

She notes that: "According with this high statement in the Strategic Plan the standard of IFLA, by antonomasia, can't be questioned at least until 2015."

Additionally, Elena raises the questions whether UNIMARC Core Programme has received such a question, and what is the status and what activities done by the Committee on Standards in which bibliographic standards are represented. She recommends joint discussions and response.

To this, I would add that joint discussions would be needed lead by the Cataloguing Section with Bibliography Section, National Libraries Section, and Information and Technology with their Semantic Web SIG. Perhaps other interested sections could be attracted outside the Division III, like rare Books and Manuscripts Section.

The results from the Survey on the ISBD use that ISBD RG plans for 2013/2014, with results and analysis prepared for the ISBD RG meeting in 2014, will be important input to the planned discussions. 


\section{Cataloguing Section - ISBD Strategy \\ Role and function of Cataloguing Section \\ Action Plan, 2011/2013}

Mission

The Cataloguing Section of IFLA strives to be the leader in international developments in cataloguing theory, activities, and standards development. The Section analyses the principles and functions of cataloguing activities for all types of materials and media, including both bibliographic and authority information, for the benefit of all kinds of users. The Section proposes and develops cataloguing rules, guidelines, and standards for bibliographic information, taking into account the developing electronic and networked environment in order to promote universal access to and exchange of bibliographic and authority information. Standardization of cataloguing at the international level so as to enable data exchange and derivation across national borders (at the core of UBC)

Hence:

- the International Cataloguing Principles

- the ISBD

- the rules for constructing access points (corporate headings), and, as an application of the principle according to which national forms for personal names and work titles should be preferred, reference documents such as Names of Persons and Anonymous Classics Even the FRBR model resulted from an effort towards the simplification of cataloguing rules. It was developed as part of the standardization endeavour, with direct consequences for the ISBD (distinction first between mandatory, conditional, and optional elements, later on between mandatory and optional elements).

That role as a standards body lies at the heart of the Section's activities. All of its other activities are related to it, and it is useful for other sections as well (most notably, the Bibliography Section).

There has been a trend, within the Section SC, for several years, towards the abandonment of standardization activities, which are handed over to other actors, outside IFLA:

- transferal of Names of Persons to VIAF or ISNI

- end of work on the Anonymous Classics

ISBD does not escape that trend, and the publication of RDA might be the pretext for the abandonment of cataloguing standardization to the benefit of a dominant cataloguing code. I think that this trend is most alarming, because it amounts to giving up IFLA's role as an international standards body in the field of cataloguing.

What would be the purpose of the Cataloguing Section, were it deprived of that role? Ought it just to survey global cataloguing practices, without being able to direct them towards greater interoperability and an openness aiming at facilitating exchanges?

In the context of digital information and the Web of data, cataloguing standardization has to evolve as it is facing novel situations and challenges. I think that we are at the verge of a transformation of bibliographic information which will prove as radical as in the 1960s-70s when the ISBD and ISBDrelated standards were being developed.

The Cataloguing Section should be the place for truly international reflections on today's cataloguing, basing on FRBR and the Web of data, and taking its specific agenda into account:

- thinking about international exchanges among national bibliographies (UBC): providing normative tools for national bibliographies and expressing these normative tools as cataloguing rules in both large and small libraries (RDA is one such cataloguing code, it was designed so as to meet first the needs of local cataloguing, and only then the needs of bibliographic interchange); 
- taking into account all countries (with their various levels of development, various cultures, etc.)

This implies an in-depth revision of the ISBD (as demonstrated by the work done on alignments) so that it can be adapted to the current environment, rather than abandoned and substituted with a code that was developed outside IFLA, with no genuine international representation.

Questions posed in the SC's discussion paper

Statements/Questions to consider:

- Has the time come when developing and maintaining a standard such as ISBD simply can't be done on a voluntary basis while still securing truly international involvement?

It seems to me that IFLA is the place that best warrants a genuine international representation, with experts from potentially every country, and any institution.

The voluntary basis is a requisite for international standardization; it also warrants neutrality. The Section has many members (including corresponding members), it is a pool of competencies that is insufficiently exploited.

- Even though RDA isn't an IFLA product it is hard to ignore that RDA most likely will be considered a de-facto-standard in large parts of the world.

So far, RDA has just the same area of influence as AACR.

It is a cataloguing code that partially refers to IFLA: it does so when it comes to IPC, FRBR/FRAD, but it regards ISBD only as a displaying format (in the continuation of AACR that only took into account the $\operatorname{ISBD}(G)$ schema, not the rules properly said).

Normally, the ISBD is a normative general framework that defines the rules for bibliographic description within the UBC framework. Those rules can then be adapted at the national level as cataloguing codes. RDA is just one such code, even though it is supranational.

It is important to keep the ISBD as the reference normative document when it comes to bibliographic description, at a higher level than any particular code.

- Will the countries using RDA put all their efforts on developing rules into RDA and not beable to contribute to ISBD? Perhaps consider ISBD less important?

This is a risk, and a prioritizing issue at the national level.

For instance, France is currently working on three issues: ISBD evolution, RDA evolution (proposals transmitted through EURIG), and revision of national rules so as to enable a FRBRized catalogue (as long as RDA has not evolved satisfactorily).

HOWEVER, if the ISBD is reaffirmed as the ONLY international reference standard, at a higher level than its various declinations as local codes (such as RDA), the JSC would better keep an eye on the evolution of IBSD, and even participate in it.

- If RDA and ISBD continue their separate development and make efforts to harmonize the content, who benefits from having two standards describing the same things and often involving the same people?

Once again, the ISBD is the international reference standard. It hovers at a higher level than national, linguistic, and cultural choices or preferences. The ISBD is needed to achieve that goal.

Besides, the ISBD is a bibliographic standard, not a cataloguing code. RDA is a cataloguing code. It is being developed by a specific community, and will always tend to privilege that community's needs. It is delusive to think that RDA, the way it is currently being developed, could evolve towards a genuine international standard that would meet everybody's needs.

- What about the obligation to countries who have based their development and trust in IFLA continuing to provide guidelines through the ISBD?

A huge responsibility weighs on IFLA. IFLA is the international reference and must continue to provide the reference framework for the cataloguing of resources. 
Besides, the ISBD is an open standard, anybody has access to it. It also is a crucial item for lessdeveloped countries that can use it as a reference for the definition of their national rules, or even directly as a cataloguing code (although the consolidated ISBD has turned more generic, making such a utilization of the ISBD more difficult).

- What about countries preferring other codes than RDA?

If such codes refer to the ISBD, this is not an issue. The ISBD is the warrant for interoperability between national codes.

- What about the social obligation to countries where they can't afford RDA? (on the other hand: can they afford to implement ISBD as it is for now?)

A number of countries do so (and have been doing so for quite some time): they use ISBD directly as a cataloguing standard.

- IFLA is the natural and truly democratic place for international cooperation: but the form the work takes must be adjusted to what is feasible. Could the ISBD evolve to a shorter, more principle-based, simple and basic standard that would be able to be incorporated into other codes but also could be used by itself by countries with no possibility to implement a more sophisticated code?

In my opinion, there is an internal contradiction in this proposal. If the ISBD is to be used directly by countries that cannot afford to adopt a more sophisticated (and, more importantly, more expensive, in terms of subscription) code, it definitely cannot be simplified and made even more generic.

The cases encountered when cataloguing must be addressed in a more detailed way, along with the recommended solution. That is what a cataloguing code is supposed to do.

It could be envisioned to split the ISBD into two distinct parts:

- the international reference standard, at a rather generic level;

- and an implementation handbook that elaborates on the main practical cases encountered in cataloguing and provides many examples, for use by countries that cannot afford to adopt a more sophisticated code or to develop a national code based on the ISBD.

As to human resources and feasibility issues, let me remind that the Cataloguing Section counts many members, and always arouses much interest at the time of elections. In the same vein, the ISBD RG counts 12 members, only a half of which are really active. If all 12 members of the ISBD RG were more strenuous, much would be achieved indeed!

Françoise Leresche

Member of the ISBD RG

Head of the Standards and Models Unit

Bibliographic and Digital Information Department

National Library of France

\section{Appendix 2}

3. Continue ISBD revision

Mission: The main purpose of the ISBD is to serve as a principal standard to promote universal bibliographic control by offering consistency when sharing bibliographic information.

The Strategy for the ISBD is under evaluation and a revised strategy is expected in 2014 3.1 Maintain and develop the ISBD content standard. Assess any amendments to be recommended by the Review Group.

3.2 Develop mapping between ISBD and the FRBR family of conceptual models in the RDF environment to inform the further development of ISBD itself, and increase the understanding of the relations between ISBD and FRBR. 
3.3 Provide leadership in encouraging harmonization of existing cataloguing rules with the ISBD through communication with rule-making bodies internationally by forming liaison relationships between each rule-making body and the ISBD Review Group.

3.4 Develop and maintain representations of the ISBD that are compatible with current electronic and semantic web environments for resource discovery and the management of metadata for use in digital and non-digital catalogues.

3.5 Maintain liaisons with the Permanent UNIMARC Committee, the ISSN Network, and the International Association of Music Libraries, Archives and Documentation Centres (IAML), with other IFLA units, and with other relevant groups to assure widespread use of the ISBD as a metadata content standard.

3.6 Encourage translations of the consolidated ISBD.

3.7 Develop training material centred on definitions, structure and the use of ISBD for rule making bodies and in general for teachers, cataloguers, etc.

\section{Appendix 3}

List of presentations and publications

1. M. Willer \& G. Dunsire. Bibliographic information organization in the Semantic Web, Oxford: Chandos, 2013.

2. M. Willer, G. Dunsire \& P. Perožić. UNIMARC in RDF Project: namespaces and linked data, IFLA, 2013, UNIMARC Open Session, 22 Aug, http://library.ifla.org/156/

3. G. Dunsire, M. Willer \& P. Perožić. Representation of the UNIMARC Bibliographic Data Format in Resource Description Framework, DC 2013, 5 Sep., http://dcevents.dublincore.org/IntConf/dc-2013/paper/view/173/91

4. G. Dunsire. IFLA in RDF (+ RDA). Lightning presentation to NISO Bibliographic Roadmap Meeting,Baltimore, USA, 15-16 Apr 2013

5. G. Dunsire. Multilingual issues in the representation of international bibliographic standards for the Semantic Web. Presentation to Sixth Multilingual Web Workshop: Making the multilingual web work, Rome, Italy, 12-13 Mar 2013

6. G. Dunsire. Granularity in Library Linked Open Data. Keynote presentation at Code4Lib 2013, Chicago, USA, 12-14 Feb 2013.

7. G. Dunsire. Mapping FRBR, ISBD, RDA, and other namespaces to DC for interoperability. Presentation to Kunnskapsorganisasjonsdagene 2013, Oslo, Norway, 7-8 Feb 2013

8. M. Willer. ISBD: information on the activities so far, and the reasons for attending to it... SCATNews No 39, June 2013, http://www.ifla.org/files/assets/cataloguing/scatn/scat-news39.pdf 


\section{APPENDIX XIV: Report from ISO TC46 Annual meetings 2013}

See document on $<$ http://www.ifla.org/cataloguing/reports $>$ 